\title{
Statistical model analysis of local structure of quaternary sphalerite crystals
}

\author{
B.V. Robouch ${ }^{1}$, A. Kisiel ${ }^{2}$, A. Marcelli ${ }^{1}$, E.M. Sheregii ${ }^{3}$, M. Cestelli Guidi ${ }^{1}$, M. Pic- \\ cinini $^{1,4}$, J. Polit ${ }^{3}$, J. Cebulski $^{3}$, A. Mycielski ${ }^{5}$, V.I. Ivanov-Omskii ${ }^{6}$ E. Sciesiñska ${ }^{7}$, \\ J. Sciesiñski ${ }^{7}$, and E. Burattini ${ }^{8}$ \\ ${ }^{1}$ INFN-Laboratori Nazionali di Frascati, Via E. Fermi, 40, Frascati I-00044, Italy \\ E-mail: robouch@Lnf.infn.it \\ ${ }^{2}$ Instytut Fizyki, Universytet Jagiellonski, Reymonta, 4, Krakow 30-059, Poland \\ ${ }^{3}$ Institute of Physics, University of Rzeszow, Rejtana, 16A, Rzeszow 35-310, Poland \\ ${ }^{4}$ Dipartimento Scienze Geologiche, Universita Roma Tre, L. go S.L. Murialdo, Rome 00146, Italy \\ ${ }^{5}$ Instytut Fizyki PAN, Al. Lotnikow, Warszawa 32/46, Poland \\ ${ }^{6}$ A.F. Ioffe Physical-Technical Institute, St. Petersburg 194021, Russia \\ ${ }^{7}$ Institute of Nuclear Physics, Krakow, Poland \\ ${ }^{8}$ University of Verona, Department of Informatics, str. Le Grazie 15, Verona 37134, Italy
}

Received October 4, 2006

\begin{abstract}
At the 2004 Ural International Winter School, we introduced the statistical strained tetrahedron model and discussed ternary tetrahedron structured crystals. The model allows one to interpret $\mathrm{x}$-ray absorption fine structure (EXAFS) data and extract quantitative information on ion site occupation preferences and on the size and shape of each elemental constituent of the configuration tetrahedra. Here we extend the model to cover quaternary sphalerite crystal structures. We discuss the two topologically different quaternary sphalerite systems: the pseudo balanced $\mathrm{A}_{1-x} \mathrm{~B}_{x} \mathrm{Y}_{y} \mathrm{Z}_{1-y}(2: 2$ cation:anion ratio), and the unbalanced $\mathrm{A}_{x} \mathrm{~B}_{x^{\prime}} \mathrm{C}_{1-x-x^{\prime}} \mathrm{Z}$ or $\mathrm{AX}_{y} \mathrm{Y}_{y^{\prime}} \mathrm{Z}_{1-y-y^{\prime}}$ (3:1 or 1:3 cation:anion ratios) truly quaternary alloy systems. These structural differences cause preference values in pseudo quaternaries to vary with the relative contents, but to remain constant in truly quaternary compounds. We give equations to determine preference coefficient values from EXAFS or phonon spectra and to extract nearest-neighbour inter-ion distances by EXAFS spectroscopy. The procedure is illustrated and tested on CdMnSeTe, GaInAsSb, and $\mathrm{ZnCdHgTe}$ quaternary alloys.
\end{abstract}

PACS: 61.43. Dq Amorphous semiconductors; metals and alloys.

Keywords: sphalerite quaternary $\mathrm{A}_{1-x} \mathrm{~B}_{x} \mathrm{Y}_{y} Z_{1-y}, \mathrm{~A}_{x} \mathrm{~B}_{x} C_{1-x-x^{\prime}} Z, A X_{y} Y_{y^{\prime}} Z_{1-y-y^{\prime}}$ systems; local crystal structure; statistical model.

\section{Introduction}

In recent years interest in multinary sphalerite structured semiconductors has developed rapidly, moving from binary to ternary, then to quaternary systems, as an extra ion-component leads to an additional degree of freedom in controlling material parameters. Indeed, the substitution of one cation by another in the cation sublattice, and the substitution of one anion by another in the anion sublattice, induces a reconstruction of the electronic structure and the phonon spectra as the composition is varied, leading to almost unique property variations. As observed, ion substitution in sphalerite crystals exhibits site occupation preferences (SOPs) linked to the thermodynamic properties of the creation of the quaternary system.

We recall here that the elemental structure of a sphalerite (zincblende) binary AZ compound is a regu- 
lar tetrahedron with alternatively at the center an A (or a Z) ion, and at its four vertices the other ion $\mathrm{Z}$ (or A). Alloying two binary compounds such as $\mathrm{AZ}+\mathrm{BZ}$ (or $\mathrm{AZ}+\mathrm{AY}$ ) leads to the formation of different ternary $\mathrm{A}_{1-x} \mathrm{~B}_{x} \mathrm{Z}$ (or $\mathrm{AY}_{y} \mathrm{Z}_{1-y}$ ) systems with $\mathrm{A}$ ions being progressively substituted by B ions (or Z by $\mathrm{Y}$ ). Thus one of the sublattices remains homogeneously monoion, while the other is modulated by the two competing ions. At the same time the tetrahedron is distorted, becoming strained (see Fig. 1 in [1]), whence the name of strained tetrahedron model introduced to treat these systems.

In the following, we use the same nomenclature introduced in [1] and used since [2-6] and define cations by $\mathrm{A}, \mathrm{B}, \mathrm{C}$, anions by $\mathrm{X}, \mathrm{Y}, \mathrm{Z}$, and the relative contents of site competing ions by $x, x^{\prime}$ for cations, and by $y, y^{\prime}$ for anions. We thus write AZ for a binary compound, $\mathrm{A}_{1-x} \mathrm{~B}_{x} \mathrm{Z}$ or $\mathrm{AY}_{y} \mathrm{Z}_{1-y}$ for a ternary system, and either $\mathrm{A}_{1-x} \mathrm{~B}_{x} \mathrm{Y}_{y} \mathrm{Z}_{1-y}(2: 2$ cation:anion ratios, referred to as Q22) or $\mathrm{A}_{1-x-x^{\prime}} \mathrm{B}_{x} \mathrm{C}_{x} \mathrm{Z}$ or $\mathrm{AX}_{y} \mathrm{Y}_{y^{\prime}} \mathrm{Z}_{1-\mathrm{y}-\mathrm{y}^{\prime}}$ (with respectively (3:1 or 1:3 cation:anion ratios) for quaternary systems. We shall refer to them, respectively, as Q31 and Q13 systems.

We immediately note that configuration-structure-wise, the quaternary systems are of two different natures: the Q31 and Q13 are quaternaries of the «unbalanced» truly-quaternary (truly-Q) type with respectively a 3:1 or $1: 3$ cation:anion ratio. Here, of the possible fifteen elemental tetrahedron configurations, ion-occupation-wise, three are binary, nine ternary, and three quaternary; indeed, the elementary tetrahedron contains respectively two, three, and four different ions. On the other hand, the Q22 type of quaternary is balanced, contains only 2:2 cation:anion species, and can be considered pseudo-quaternary (pseudo-Q). Ion-occupation-wise Q22 can have sixteen tetrahedron configurations, of which four are binary, and twelve ternary. None of its sphalerite tetrahedron configurations can canonically be «quaternary». Indeed, in a Q22 system, each cation (anion) has only two anions (cations) of the opposite polarity that can occupy the four vertex sites of the sublattice. Implanting into a vertex position of an ion with the same polarity as the central ion corresponds to introducing it into the opposite sublattice, i.e., creating an antisite occupation point defect. Thus we can consider the four ternary constituents (each with its tetrahedron configurations) as dissolved in a quaternary medium, with a $\mathrm{A}_{1-x} \mathrm{~B}_{x} \mathrm{Y}_{y} \mathrm{Z}_{1-y}$ consisting of $\mathrm{A}_{1-x} \mathrm{~B}_{x} \mathrm{Y}$ or $\mathrm{AY}_{y} \mathrm{Z}_{1-y}, \mathrm{~A}_{1-x} \mathrm{~B}_{x} \mathrm{Z}$ or $\mathrm{BY}_{y} \mathrm{Z}_{1-y}$.

The Q31 (Q13) and Q22 systems are usually chemically identified as quaternary alloys. However, there is a basic structural difference between the pseudo-Q and the truly- $Q$ systems. Indeed, while a truly- $Q$ has one of its sublattices with a homogeneously monoionic population, the complementary sublattice is modulated by the three ion species competing for each site. This leads to a crystal structure with alternatively a homogenous ion-shell, followed by a heterogeneous shell with site-competing ions. On the other hand, in pseudo-Q the sublattices, and hence the successive ion shells, are all heterogeneous, have successively anions or cations, intracompeting for site occupation in that shell. While the denomination is a consequence of the existing configurations, the occurrence of successive homogeneous $\backslash$ inhomogeneous shell structures conditions basic differences in the properties of the two classes of quaternaries. The topological differences between quaternary sphalerite Q31 (Q13) and Q22 structured systems impose different statistical model approaches and thus the statistical analysis of the pseudo and truly-Q compounds is not a simple generalisation. This explains why, after the Q22 compound analysis [4], an ad hoc statistical strained tetrahedron model for quaternary sphalerite Q31 and Q13 systems is developed in Ref. 7.

An understanding of the properties of quaternary alloys requires accurate and systematic structural investigations using different techniques such as neutron scattering, extended x-ray absorption fine structure (EXAFS) [8,9] or far infrared (FIR) [10,11] vibrational spectroscopy. In particular the last two methods yield respectively information on the real local structure and on the collective internal vibrations (phonons) of the investigated systems.

As generally reported, ternary tetrahedron coordinated $\mathrm{A}_{1-x} \mathrm{~B}_{x} \mathrm{Z}$ and $\mathrm{AY}_{y} \mathrm{Z}_{1-y}$ systems ([12-15] for FIR and [16-28] for EXAFS), as well as balanced quaternaries of type $\mathrm{A}_{1-x} \mathrm{~B}_{x} \mathrm{Y}_{y} \mathrm{Z}_{1-y}$ (such as GaInAsSb [29] for EXAFS, CdMnSeTe [30] for EXAFS and [6,31] for FIR, analyzed in [32], ZnCdSeTe [33] for FIR), and unbalanced quaternary $\mathrm{A}_{1-x-x^{\prime}} \mathrm{B}_{x^{\prime}} \mathrm{C}_{x} \mathrm{Z}$ (such as MnCdHgTe [34], ZnCdHgTe [35,36]), or $\mathrm{AX}_{y} \mathrm{Y}_{\mathrm{y}^{\prime}} \mathrm{Z}_{1-\mathrm{y}-\mathrm{y}^{\prime}}$ system FIR spectra all exhibit SOPs; such preferences are linked to the thermodynamic properties of each system.

To extract quantitative information on the local structure of tetrahedron configured crystals, we originally developed the statistical strained tetrahedron model to return site preferences as well as sizes and shapes of the elemental tetrahedron configurations from sphalerite and some wurzite EXAFS experimental data for ternary semiconductor alloys $[1,2]$. Successively, the model was expanded to treat ternary $\mathrm{M}_{3}\left(\mathrm{XX}^{\prime}\right)_{1}$ type intermetallide alloys [3] and then to interpret FIR spectra of ternary sphalerite structure [4,5]. To our knowledge no EXAFS data for truly-Q systems are available in the literature. 
For wurzite systems, the model returns a valid analysis of EXAFS data provided the electron wave backscattering from ions beyond the next nearest neighbours (NNN) remains negligible with respect to that from nearest neighbours (NN) and from NNN ions; the same restriction applies to both balanced pseudo-Q [6] and unbalanced truly-Q [7] sphalerite structured systems.

The basic assumptions or axioms of the statistical model are $[1,2]$ :

1. The elemental tetrahedra are free to have different sizes and shapes (Fig. 1 in $[1,2]$ ).

2. Bernoulli binomial polynomials with preference weight coefficients describe ion-pair and configuration populations.

3. All NNNs and further fills are determined by NN preferences.

4. The total coordination number is conserved when dilution varies (this defines the range of values with physical meaning and imposes bounds on coefficient values).

5. The formation of each ternary or quaternary elemental configuration proceeds, respecting mass conservation, until complete exhaustion of one of the binary ingredients, or of both simultaneously as in the random case. This axiom is crucial to understand and interpret SOP estimations returned from EXAFS and FIR analysis. Then to interpret EXAFS distance data [1]:

6. All nineteen elemental inter-ion ternary distances are tetrahedron constrained.

7. Elemental volumes of the two sublattices, for each of the three strictly ternary configurations, relax pair-by-pair to common values (i.e., three volume relaxation constraints [VRC] on the distance parameters). For FIR spectra, the lines issued from the different configurations by a given ion ij-dipole have an invariant $[4,5]$.

$6^{\prime}$. Line width shape ${ }^{i j} \Gamma$ and

$7^{\prime}$. Oscillator strength ${ }^{i j} s$.

We compare the statistical models of balanced and unbalanced quaternary compounds and quantify preferences using both EXAFS and FIR experimental data. We attempt to extract NN inter-ion distances from EXAFS data. Finally, we apply the model to balanced quaternary alloys CdMnSeTe, GaInAsSb and the available unbalanced quaternary ZnCdHgTe phonon spectra [35,36].

To facilitate comprehension of the text, we confine all the equations to the appendix, but refer to the published articles where they are derived and presented in extensio so that the reader can interpret EXAFS data or FIR vibrational spectra and extract quantitative information on SOP coefficients, or for just EXAFS, the elemental configuration distances between $\mathrm{NN}$ and $\mathrm{NNN}$ ions.

\section{General considerations}

Sphalerite (zincblende) systems are face centered cubic (fcc) structure with tetrahedron coordinated configurations with an anion (cation) at the center and a cation (anion) at each of the four vertices. Depending on whether we have at the vertices one, two, or three types of ions (with the extra ion type at the center), the systems are respectively binary, ternary, or quaternary. In all cases, the cations form one of the two crystal sublattices, while the anions constitute the complementary sublattice shifted by a $1 / 4$ of the length of the main diagonal of the elemental cube.

A binary AZ compound consists of regular tetrahedra $T_{0}\left(a_{\mathrm{AZ}}\right)$, is defined by its lattice constant $a_{\mathrm{AZ}}$ with inter-ion distances ${ }^{\mathrm{AZ}} d_{0}=3^{1 / 2} a_{\mathrm{AZ}} / 4$; ${ }^{\mathrm{AA}} d_{0}=$ $={ }^{\mathrm{ZAZ}} d_{0}=a_{\mathrm{AZ}} / 2^{1 / 2}$, and its first and second shells are strict spheres, one of cations, the other of anions; thus, determining $a_{\mathrm{AZ}}$ by interferometer spectrometry, defines the distribution and elemental dimensions.

A ternary $\mathrm{A}_{1-x} \mathrm{~B}_{x} \mathrm{Z}$ (or $\mathrm{AY}_{y} \mathrm{Z}_{1-y}$ ) system is obtained by a progressive substitution of A by $\mathrm{B}$ ions (or $\mathrm{Z}$ by $\mathrm{Y}$ ) in the configuration tetrahedra $\left\{T_{k}\right\}_{k=0,4}$, where $k$ stands for the number of substituting ions B (or Y) at the vertices. Still, one of the two sublattices remains strictly homogeneous mono-ionic, while the other is modulated by the two competing ions. Competition is conditioned by the preference of the one competing ion to the other; thus the ion distribution departs from pure randomness. At the same time, since competing ions have different radii, the tetrahedron becomes distorted i.e., strained (Fig. 1 in [1]).

A quaternary sphalerite structured semiconductor system results from a further substitution of yet another ion into a ternary alloy. Such an intrusion may or may not keep one of the two sublattices strictly homogeneous mono-ionic. When $\mathrm{A}_{x} \mathrm{~B}_{x^{\prime}} \mathrm{C}_{1-x-x} \mathrm{Z}$ or $\mathrm{AX}_{y} \mathrm{Y}_{y^{\prime}} \mathrm{Z}_{1-y-y^{\prime}}$ are generated, the «unbalanced» Q31 and Q13 have one sublattice mono-ionic homogeneous, while the second is modulated by the three competing ions and hence are truly-Q. Their configuration tetrahedra are $\left\{T_{k, j}\right\}_{k=0,4 ; j=0,4-k}$, where $k$ and $j$ stand for the number of substituting ions $\mathrm{A}$ and $\mathrm{B}$ (or $\mathrm{X}$ and $\mathrm{Y}$ ) at the vertices. On the other hand, in a $\mathrm{A}_{1-x} \mathrm{~B}_{x} \mathrm{Y}_{y} \mathrm{Z}_{1-y}$ system with a balanced Q22 with 2:2 cation:anion ratio competition occurs in both sublattices. Indeed, a Q22 system cannot (excluding antisite point defects) have a canonical quaternary configuration and hence is a pseudo-Q [6]. Thus a Q22 $\mathrm{A}_{1-x} \mathrm{~B}_{x} \mathrm{Y}_{y} \mathrm{Z}_{1-y}$ is a mixture of four ternary systems, each with a distinct c-ion $(\mathrm{A}, \mathrm{B}, \mathrm{Y}$, or $\mathrm{Z})$ at the center; their configuration tetra-

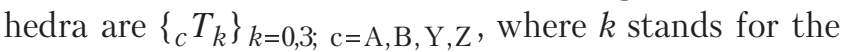
number of substituting ions $\mathrm{Y}$ (or B) at the vertices. 
In the absence of SOPs, ion distribution throughout the configuration sites is random. The ion distribution in the successive shells with $N$ sites ( 4 in the $\mathrm{NN}$ shell, 12 in the NNN shell) around the central c-ion are described by Bernoulli binomials.

In the case of two competing ions (occupation of $N$ sites by $m \mathrm{~A}$ ions and hence $(N-m)$ B ions with relative contents $x$ and $1-x$ ), by

$$
\left\{p m^{[N]}(x)=C_{m}^{N} x^{m}(1-x)^{N-m}\right\}_{m=0, N}
$$

with $C_{m}^{N}=N ! /[m !(N-m) !]$ the binomial coefficient and

$$
\sum_{m=0, N}\left\{p m^{[N]}(x)\right\} \equiv 1 ; \quad \sum_{m=0, N}\left\{m p_{m}^{[N]}(x)\right\} \equiv N x .
$$

In the case of three competing ions, as for truly- $Q$ systems (with occupation of $N$ sites by $k \mathrm{~A}$ ions, $j \mathrm{~B}$ ions and $(N-k-j) \mathrm{C}$ ions, with respective relative contents $x, x^{\prime}$, and $\left(1-x-x^{\prime}\right)$ ) (see for instance [37]) by

$$
\begin{gathered}
\left\{p_{k j}^{[N]}\left(x, x^{\prime}\right)=C_{k}^{N} x^{k} C_{j}^{N-k} x^{\prime j} \times\right. \\
\left.\times\left(1-x-x^{\prime}\right)^{N-k-j}\right\}_{k=0, N ; j=0, N-k}
\end{gathered}
$$

a set of fifteen terms, one for each configuration, with

$$
\sum_{k=0,4} \sum_{j=0,4-k}\left\{p_{k j}\left(x, x^{\prime}\right)\right\} \equiv 1 \text { while } 0 \leq\left(x+x^{\prime}\right) \leq 1 \text {. }
$$

Whenever the system presents preferences, the distribution is no longer random, and to describe probabilities, SOP weight coefficients $W$ are applied to each Bernoulli binomial [1]. Binary weight coefficients are evidently $W_{\text {binary }} \equiv 1$. Thus, a ternary with its three truly ternary configurations and two binary requires three $\left\{W_{k}\right\}_{k=1,3}$ SOP coefficients [1], while the Q22, mixture of four ternary systems, requires $12(=4 \cdot 3)$ $\left\{{ }_{c} W_{k}\right\}_{k=1,3 ; c=\mathrm{A}, \mathrm{B}, \mathrm{Y}, \mathrm{Z}}$ coefficients (Table 1 and [6]). The truly-Q with $\left\{W_{k j}\right\}_{k=0,4 ; j=0,4-k}$ coefficients, with the binary $W_{00} \equiv W_{04} \equiv W_{40} \equiv 1$ (Table 4 ), needs 12 coefficients. Since all probability coefficients are nonnegative, the SOP $W$ coefficient values are restricted. Because preferences imply unbalanced populations (with respect to random, $W \neq 1$ ), the excess (or scarcity) of one of the constituent ions competing for sites with respect to stoichiometry determined populations. Actually when the minor constituent is no more available, the excess remains as a binary. Respect to the random case the resulting nonbinary configuration probabilities are depressed each time any $W$-coefficient $\neq 1$, and the corresponding depression factor $C_{W \neq 1}$ appears, with the ions in excess going to enhance the corresponding binary populations, see Appendix 1.

Once the values of the SOP coefficients are known, all coordination numbers $(\mathrm{CN})$, see Appendix 2, and configuration probabilities $\left(P_{\text {ternary }}: P_{k}(x) ; P_{\text {pseudo-Q }}\right.$ : $\left.{ }_{c} P_{k}(x, y) ; P_{\text {truly-Q }}: P_{k j}(x, y)\right)$ as functions of the respective ion relative contents $\left(x, x^{\prime}, y, y^{\prime}\right.$ as appropriate for each system) are fully determined, see Appendix 3. From these quantities we get the expressions for the evaluation of the elemental configuration inter $i j$-ion distances $\left({ }_{i}^{j} d\right)$, derivable from EXAFS $\left\langle{ }_{i}^{j} \mathrm{CN}\right\rangle$ and $\left\langle{ }_{i}^{j} d\right\rangle$ (see Appendix 4), or from FIR spectra the preference SOP coefficients of the multinary (see Appendix 5). In the following for the sake of clarity, we will use the above-mentioned mnemonic symbolism rather than the traditional $R_{j}$ and $\varphi_{j}$ EXAFS parameters.

We now concentrate on the two quaternary systems Q22 and Q31 or Q13 and outline the consequence on SOPs: Pseudo-Q is a mixture of ternaries, so SOPs drift with contents! On the other hand, truly-Q SOP coefficient values remain invariant as the relative ion contents vary!

\section{Pseudo-quaternary $\mathrm{A}_{1-x} \mathrm{~B}_{x} \mathrm{Y}_{y} \mathrm{Z}_{1-y}$ sphalerite structure}

Tetrahedron coordinated sphalerite structure quaternary systems of type $\mathrm{A}_{1-x} \mathrm{~B}_{x} \mathrm{Y}_{y} \mathrm{Z}_{1-y}$ consist exclusively of binary and ternary elemental tetrahedra, four of the first and four of the latter, each one with three configurations, i.e., a total of sixteen elemental tetrahedron configurations (Table 1). Counting the dipoles, we have 4 from binary + (4.3.2) from the ternary configurations; i.e., potentially a total of up to 28 phonon lines in 4 basic bands (Fig. 1) of closely overlapping lines. However, these configurations cannot contain simultaneously all four constituent atoms in the same elemental tetrahedron; as a consequence we can consider each ternary tetrahedron composition as being diluted in the quaternary compound. Thus, $\mathrm{A}_{1-x} \mathrm{~B}_{x} \mathrm{Y}_{y} \mathrm{Z}_{1-y}$ EXAFS data can be treated by using the strained tetrahedron model which, originally developed to deal with ternary systems, has already exhibited excellent agreement with numerous experimental data $[1,2]$.

\begin{tabular}{|c|c|c|c|c|c|}
\hline$j_{\mathrm{B}}=\backslash k_{\mathrm{A}}=$ & 0 & 1 & 2 & 3 & 4 \\
\hline 0 & $\mathbf{C Z}$ & ${ }^{1} \mathrm{~A}^{3} \mathrm{C}: \mathrm{Z}$ & ${ }^{2} \mathrm{~A}^{2} \mathrm{C}: \mathrm{Z}$ & ${ }^{3} \mathrm{~A}^{1} \mathrm{C}: \mathrm{Z}$ & $\mathrm{AZ}$ \\
\hline 1 & ${ }^{1} \mathrm{~B}^{3} \mathrm{C}: \mathrm{Z}$ & ${ }^{1} A^{1} B^{2} C: Z$ & ${ }^{2} A^{1} B^{1} C: Z$ & ${ }^{3} \mathrm{~A}^{1} \mathrm{~B}: \mathrm{Z}$ & \\
\hline 2 & ${ }^{2} \mathrm{~B}^{2} \mathrm{C}: \mathrm{Z}$ & ${ }^{1} A^{2} B^{1} C: Z$ & ${ }^{2} \mathrm{~A}^{2} \mathrm{~B}: \mathrm{Z}$ & & \\
\hline 3 & ${ }^{3} \mathrm{~B}^{1} \mathrm{C}: \mathrm{Z}$ & ${ }^{1} \mathrm{~A}^{3} \mathrm{~B}: \mathrm{Z}$ & & & \\
\hline 4 & BZ & & & & \\
\hline
\end{tabular}

Table 1. The 16 tetrahedron configurations of a quaternary $\mathrm{A}_{1-x} \mathrm{~B}_{x} \mathrm{Y}_{2} \mathrm{Z}_{1-y}$ system: 4 binary $(\mathbf{A Y}, \mathbf{A Z}, \mathbf{B Y}, \mathbf{B Z})+$ $(4 \cdot 3)$ ternary $\left(\mathrm{A}_{1-x}^{1-y} \mathrm{~B}_{x} \mathrm{Y}, \mathrm{A}_{1-x} \mathrm{~B}_{x} \mathrm{Z}, \mathrm{AY}_{y} \mathrm{Z}_{1-y}, \mathrm{BY}_{y} \mathrm{Z}_{1-y}\right)=16$. No pure quaternary configuration occurs. 


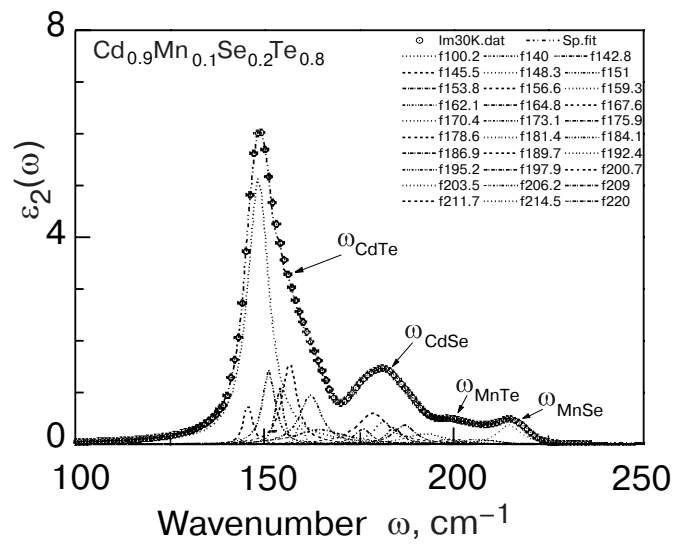

Fig. 1. Deconvolution of the $\varepsilon_{2}(\omega, T)$ function obtained by the KK-transform of the reflectivity spectrum of the $\mathrm{Cd}_{0.9} \mathrm{Mn}_{0.1} \mathrm{Se}_{0.2} \mathrm{Te}_{0.8}$ sample measured at $T=30 \mathrm{~K}$ (closed circles). Sp-fit is the obtained best fit curve; the 30 pseudo Voigt-shaped lines are labelled «f» followed by their phonon frequency. Experimental $\omega$-resolution $=2 \mathrm{~cm}^{-1} ; \varepsilon_{2}$ uncertainty \pm 0.06 ; error bars are shown. The four main phonon bands [6] are addresed.

To determine ion site occupation preferences of quaternary systems, we applied this model to GaInAsSb [29] data available in the literature and to our EXAFS data for CdMnSeTe [30], and we compared the results with those derived from ternary EXAFS data for GaInAs [16] and CdMnTe [17,18]. In both sets, as the ternary is diluted in the quaternary system, different preference values respect to the pure ternary are observed. The present analysis of the experimental reflectivity FIR phonon spectra of quaternary CdMnSeTe crystals [6] confirms the model predictions and leads to a consistent interpretation of the experimental data for $\mathrm{A}_{1-x} \mathrm{~B}_{x} \mathrm{Y}_{y} \mathrm{Z}_{1-y}$ quaternary systems [6]. From Table 1, the total number of dipole contributions is 4 from binary $+(12.2)$ from the ternary configurations; i.e., we expect up to 28 phonon lines in 4 basic bands (Fig. 1).

\section{Truly-quaternary $\mathrm{A}_{x} \mathbf{B}_{x^{\prime}} \mathrm{C}_{1-x-x^{\prime}} \mathrm{Z}$ or $\mathrm{AX}_{y} \mathrm{Y}_{y^{\prime}} \mathrm{Z}_{1-y-y^{\prime}}$ sphalerite structured systems}

Tetrahedron coordinated sphalerite quaternary systems of the type $\mathrm{A}_{x} \mathrm{~B}_{x^{\prime}} \mathrm{C}_{1-x-x^{\prime}} \mathrm{Z}$ or $\mathrm{AX}_{y} \mathrm{Y}_{y^{\prime}} \mathrm{Z}_{1-\mathrm{y}-\mathrm{y}^{\prime}}$ consist of fifteen elemental tetrahedra, each containing at the center one ion and at the vertices one, two, or three competing ions, i.e., respectively binary, ternary, and truly-Q in composition (Table 2). Counting the dipoles, we have 3 from binary $+(3 \cdot 3 \cdot 2)$ from the ternary $+(3 \cdot 3)$ from the quaternary configurations; i.e., up to 30 phonon lines in 3 basic bands (Fig. 2).

By tuning the x-ray energy to the $K$ - (or $L$ - or $M$-) edge of one of the constituent ions $\langle\mathrm{C} »($ where $\mathrm{c}=\{\mathrm{A}$, $\mathrm{B}, \mathrm{C}$, or $\mathrm{Z}\}$ of the $\mathrm{A}_{x} \mathrm{~B}_{x^{\prime}} \mathrm{C}_{1-x-x^{\prime}} \mathrm{Z}$ quaternary) we probe the average (over the sample and over all configura- tions) local structure around the selected atom; one thus may retreive: the relative number of ions of a given type around it, i.e., ion pairs or coordination numbers $(\mathrm{CN}),<_{\text {center }}{ }^{\text {vertex }} \mathrm{CN}\left(x, x^{\prime}\right)>$; inter-ion distance ${ }_{\text {center }}{ }^{\text {vertex }}<d\left(x, x^{\prime}\right)>$ between the selected c-ion and the $\mathrm{NN}$ or NNN vertex-ions around it.

Table 2. The 15 tetrahedron configurations of the quaternary $\mathrm{A}_{x} \mathrm{~B}_{x^{\prime}} \mathrm{C}_{1-x-x^{\prime}} \mathrm{Z}$ or $\mathrm{AX}_{y} \mathrm{Y}_{y}, \mathrm{Z}_{1-\mathrm{y}-y^{\prime}}$ system: 3 binary ( $\mathrm{AZ}$, $\mathbf{B Z}, \mathbf{C Z})+(3 \cdot 3)$ ternary $\left(\mathrm{A}_{1-x} \mathrm{~B}_{x} \mathrm{Z}, \mathrm{C}_{1-x} \mathrm{~B}_{x} \mathrm{Z}, \mathrm{AY}_{y} \mathrm{Z}_{1-y}\right.$, $\left.\mathrm{BY}_{y} \mathrm{Z}_{1-y}\right)+(1 \cdot 3)$ quaternary $\left({ }^{1} \boldsymbol{A}^{1} \boldsymbol{B}^{2} \boldsymbol{C}: \boldsymbol{Z},{ }^{2} \boldsymbol{A}^{1} \boldsymbol{B}^{1} \boldsymbol{C}: \boldsymbol{Z}\right.$, $\left.{ }^{1} \boldsymbol{A}^{2} \boldsymbol{B}^{\mathbf{C}} \boldsymbol{C}: \boldsymbol{Z}\right)=15$

\begin{tabular}{|c|c|c|c|c|c|}
\hline$\underline{j_{\mathrm{B}}}=\backslash k_{\mathrm{A}}=$ & 0 & 1 & 2 & 3 & 4 \\
\hline 0 & $\mathrm{CZ}$ & ${ }^{1} \mathrm{~A}^{3} \mathrm{C}: \mathrm{Z}$ & ${ }^{2} \mathrm{~A}^{2} \mathrm{C}: \mathrm{Z}$ & ${ }^{3} \mathrm{~A}^{1} \mathrm{C}: \mathrm{Z}$ & $\mathrm{AZ}$ \\
\hline 1 & ${ }^{1} \mathrm{~B}^{3} \mathrm{C}: \mathrm{Z}$ & ${ }^{1} A^{1} B^{2} C: Z$ & ${ }^{2} A^{1} B^{1} C: Z$ & ${ }^{3} A^{1} B: Z$ & \\
\hline 2 & ${ }^{2} \mathrm{~B}^{2} \mathrm{C}: \mathrm{Z}$ & ${ }^{1} A^{2} B^{1} C: Z$ & ${ }^{2} \mathrm{~A}^{2} \mathrm{~B}: \mathrm{Z}$ & & \\
\hline 3 & ${ }^{3} \mathrm{~B}^{1} \mathrm{C}: \mathrm{Z}$ & ${ }^{1} \mathrm{~A}^{3} \mathrm{~B}: \mathrm{Z}$ & & & \\
\hline 4 & $\mathrm{BZ}$ & & & & \\
\hline
\end{tabular}

The NN average coordination numbers $\left\langle{ }_{i}^{y} \mathrm{CN}\left(x, x^{\prime}\right)\right\rangle$ are a «count» of ij-ion-pair numbers, explicitly the average number of $\langle\mathrm{j} »$ ions around a central $\ll \mathrm{i} \gg$ ion. For the truly- $Q$ structure with alternate homogeneous mono ion shells around the «competing» ions $\mathrm{A}, \mathrm{B}, \mathrm{C}$, the $\mathrm{NN}$ shells have only Z-ions, i.e., $\left\langle{ }_{i}^{Z} \mathrm{CN}\left(x, x^{\prime}\right)\right\rangle \equiv 4$, while around the $\mathrm{Z}$-ions the expressions of probabilities of the «competing» A, B, C ions occupying the four NN sites, are given in the Appendix 2. Using the configuration probabilities $\left\{P_{k j}\left(x, x^{\prime}\right)\right\}_{k=0,4 ; j=0,(4-k)}$ (Appendix 3 ) that duly account for stoichiometry, the expressions for the average $\mathrm{NN}$ inter-ion distances $\left\langle z^{\text {vertex }} d\left(x, x^{\prime}\right)\right\rangle$ are given in Appendix 4 [1].

To interpret far infrared reflection \transmission spectra, the Kramers-Kronig transformation is ap-

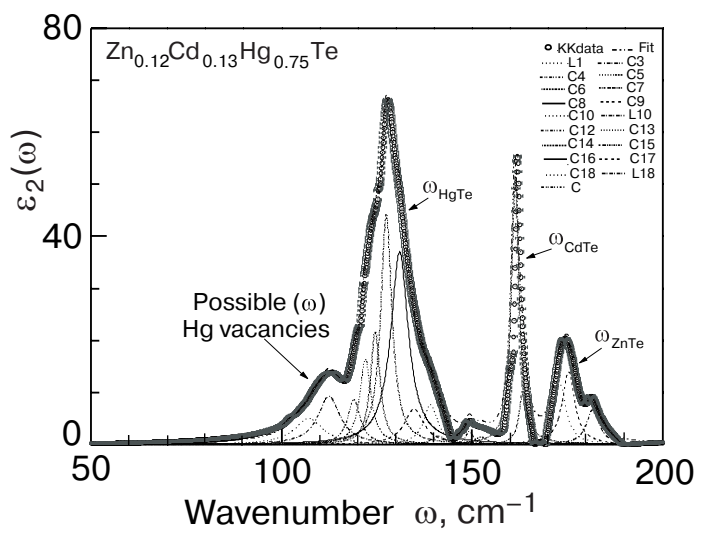

Fig. 2. Deconvolution of a $\mathrm{Zn}_{0.12} \mathrm{Cd}_{0.13} \mathrm{Hg}_{0.75} \mathrm{Te}$ spectrum (using Lorentzian line shapes). Experimental $\omega$-resolution $=2 \mathrm{~cm}^{-1} ; \varepsilon_{2}$ uncertainty bars $= \pm 0.63$; error bars are shown. Note the three main bands, and possibly Hg-vacancy point defects [7]. 
plied (carrefully as the experimental $\omega$-range is finite), to obtain the corresponding complex dielectric constant $\varepsilon\left(\omega, x, x^{\prime}\right)$, whose general expression is [10,11]:

$$
\begin{aligned}
& \varepsilon\left(\omega, x, x^{\prime}\right)=\varepsilon_{\infty}+\sum_{j=1, n}\left\{S_{j} \omega_{j}^{2} /\left[\left(\omega^{2}-\omega_{j}^{2}\right)-i \omega \Gamma_{j}\right]\right\}- \\
& \left.-\varepsilon_{\infty} \omega_{\text {plasma }}^{2} / \omega(\omega+i \Gamma)\right]=\varepsilon_{1}\left(\omega, x, x^{\prime}\right)+i \varepsilon_{2}\left(\omega, x, x^{\prime}\right)
\end{aligned}
$$

where $\varepsilon_{1}\left(\omega, x, x^{\prime}\right)$, and $\varepsilon_{2}\left(\omega, x, x^{\prime}\right)$ are respectively, the real and imaginary parts of the dielectric constant; $\varepsilon\left(\omega, x, x^{\prime}\right)$. In the equation, the first term $\varepsilon_{\infty}$ is the optic dielectric constant; the second term represents contributions by lattice and defect vibration modes, with $\omega_{j}$ the frequency of the phonon mode, $\Gamma_{j}$ the damping constant (or line half-width), and $S_{j}$ the (dimensionless) nary configurations, and three phonons from each of the quaternary (see Appendix 5). The total number of phonon lines and the corresponding number of mode bands is particular to each system. The oscillator strength of each phonon is determined by the configuration probabilities $P_{k}(x)$ (taking into account the SOPs, see Appendix 3) and the specific oscillator strengths of the binary compounds involved. The explicit expression of the equation for $\varepsilon_{2}(\omega)$ is given in Appendix 5 .

\section{Discussion and conclusions}

Experimental data of EXAFS and FIR of quaternary systems are rather scarce. We retrieved and processed EXAFS data of pseudo-Q GaInAsSb [29] (Fig. 3 and Table 3) and our previous data of CdMnSeTe [30]

\begin{tabular}{|c|c|c|c|c|c|c|c|c|c|c|c|c|c|}
\hline \multirow{2}{*}{ GaInAs $\mathrm{Sb}_{1-y}$} & \multirow{2}{*}{$\begin{array}{c}c^{T_{k}} \\
c=\mathrm{As}\end{array}$} & \multicolumn{3}{|c|}{ As $W_{k}$} & \multicolumn{3}{|c|}{ As $C_{k}$} & \multicolumn{3}{|c|}{$\underset{\mathrm{As}}{\mathrm{Ga}} d_{k}$} & \multirow{2}{*}{\multicolumn{2}{|c|}{$\underset{\text { As }}{\operatorname{In}} d_{k}$}} & \multirow{2}{*}{$\begin{array}{c}{[\AA]} \\
3 \\
\end{array}$} \\
\hline & & $\mathrm{k}=1$ & 2 & 3 & 1 & 2 & 3 & $k=1$ & 2 & 3 & & & \\
\hline \multicolumn{14}{|l|}{$\operatorname{GaInAs}_{(\text {in } Q \text { ) }}$} \\
\hline$y_{\mathrm{As}}=0.05$ & & 1.88 & 1.54 & 1.32 & & & & 2.81 & 2.45 & - & 2.66 & 2.53 & - \\
\hline$x_{\mathrm{Ga}}=\{0.2,0.5,0.65$, & & & & & & & & & & & & & \\
\hline $0.8,0.95\}$ & & & & & 0.71 & 0.46 & 0.05 & & & & & & \\
\hline$y_{\mathrm{As}}=0.10$ & & 1.93 & 1.59 & 1.33 & & & & 2.84 & 2.34 & - & 2.65 & 2.49 & - \\
\hline$x_{\mathrm{Ga}}=\{0.1,0.5,0.9\}$ & & & & & 0.69 & 0.41 & 0 & & & & & & \\
\hline both together & & 1.89 & 1.56 & 1.33 & 0.70 & 0.44 & 0 & 2.80 & 2.44 & - & 2.65 & 2.52 & 一 \\
\hline $\mathrm{GaInAs}_{(\text {as } T)}$ & & 1.05 & 0.25 & 0.58 & 0.85 & 0.25 & 0.58 & 2.49 & 2.42 & 2.48 & 2.59 & 2.60 & 2.61 \\
\hline
\end{tabular}

Table 3. $\mathrm{Ga}_{1-x} \mathrm{In}_{x} \mathrm{As}_{y} \mathrm{Sb}_{1-y}$ [6]: comparison of $\mathrm{NN}$ values for $\mathrm{GaInAs}_{(\text {as } \mathrm{T})}[1,17]$ with those of $\mathrm{GaInAs}_{(\text {in } \mathrm{Q})}$.

oscillator strength (OS) of the spectrum component $n$ lines; the third, the Drude term is related to plasma contribution with $\omega_{\text {plasma }}$ the plasma frequency, and $\Gamma=1 / \tau$, where $\tau$ is the scattering time of free carries, apparent in semimetal alloys. The line profiles are assumed to be either Lorentzian, $\quad\left(y_{L}(\omega)=\right.$ $\left.=s_{L} \Gamma_{L}^{2} \omega^{2} /\left[\left(\omega^{2}-\omega_{0 L}^{2}\right)^{2}+\Gamma_{L}^{2} \omega^{2}\right][10]\right)$, indicated at low temperatures, or whenever $\Gamma_{L} \gg \Gamma_{G}$ or Gaussian $\left(y_{G}(\omega)=s_{G} \exp \left\{-\left[\left(\omega-\omega_{0 G}\right) / \Gamma_{G}\right]^{2}\right\}\right.$ whenever the experimental line profile half width is greater than the natural spectral half width $\Gamma_{G} \gg \Gamma_{L}$; or a linear combination of both, referred to as pseudo-Voigt line shaped, $y_{\text {Voigt }}(\omega)=\eta y_{G}+(1-\eta) y_{L}$ whenever $\Gamma_{L} \approx$ $\approx \Gamma_{G}$; with $0 \leq \eta \leq 1$, pseudo-Voigt covers both extreme and intermediate line shapes, leading to better quality best fits. A detailed comparative study of the spectral fit by Gaussian, Lorentzian, or pseudo-Voigt line shapes can be found in Ref. 40. Each line is associated to an ij-dipole ( $i=\mathrm{A}, \mathrm{B}$, or $\mathrm{C}, j=\mathrm{Z}, \mathrm{Y}$, or $\mathrm{X}$ ) of the different configurations: one phonon from each of the binary configurations, two phonons from each of the three ter-

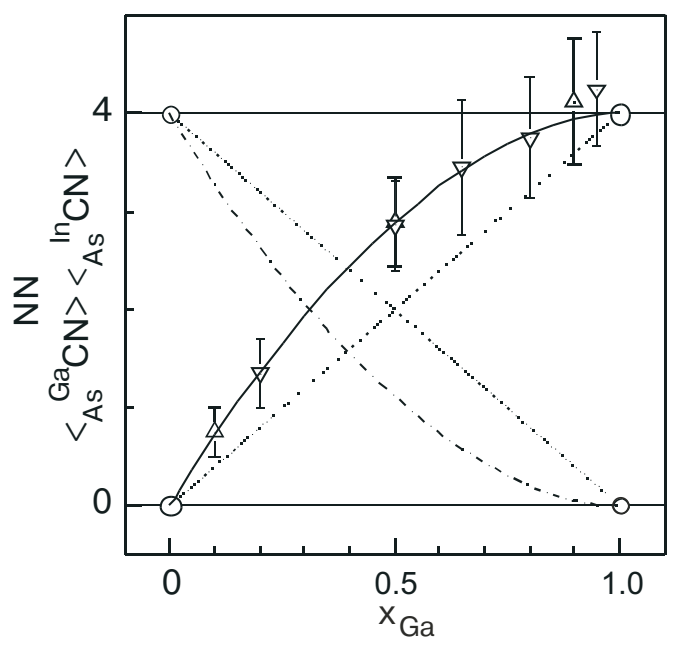

Fig. 3. Analysis of $\mathrm{Ga}_{1-x} \mathrm{In}_{x} \mathrm{As}_{y} \mathrm{Sb}_{1-y} \quad$ EXAFS $\left\langle\mathrm{CN}\left(x_{\mathrm{Ga}}\right)\right\rangle_{\text {As K-edge }}$ data [31]. Experimental points (triangles up $y=0.1$, triangles down $y=0.2$ ); derived curves $\left\langle\mathrm{Ga} C N\left(x_{\mathrm{Ga}}\right)\right\rangle$ (solid); $\left.{ }_{\mathrm{As}}^{\mathrm{n}} \mathrm{CN}\left(x_{\mathrm{Ga}}\right)\right\rangle$ (dash dotted). Random limits (dotted). 
(Fig. 4 and Table 4), a system for which also the FIR reflectivity spectra are available [6]. From these the imaginary part of the respective dielectric functions $\varepsilon_{2}(\omega)$ were obtained (Fig. 1), and the data interpreted using the strained tetrahedron model. To our knowledge no truly-Q EXAFS data are available in the literature. $\mathrm{ZnCdHgTe} \mathrm{FIR} \mathrm{spectra} \mathrm{are} \mathrm{available}[35,36]$ and the analysis [7], partially presented here (Fig. 2) is still in progress. Note that using pseudo-Voigt line shapes gives a better fit (Fig. 1), than using Lorentzian (Fig. 2), as observed in Refs. [6,38].

Table 4. $\mathrm{Cd}_{1-x} \mathrm{Mn}_{x} \mathrm{Se}_{y} \mathrm{Te}_{1-y}$ : comparison of $\mathrm{NN}$ values for $\mathrm{CdMnTe}_{(\text {as } T)}[1,18,19]$ with those of CdMnTe (in $\left.Q\right)$ [6].

\begin{tabular}{|c|c|c|c|c|c|c|c|}
\hline \multirow[t]{2}{*}{ Ternary } & \multirow{2}{*}{$\begin{array}{c}{ }^{T T_{k}} \\
c \\
\end{array}$} & \multicolumn{3}{|c|}{${ }_{c} W_{k}$} & \multicolumn{3}{|c|}{${ }_{c} C_{k}$} \\
\hline & & $\mathrm{k}=1$ & 2 & 3 & $k=1$ & 2 & 3 \\
\hline \multirow[t]{3}{*}{$\mathrm{MnSeTe}_{(\text {in } Q)}$} & $\mathrm{Mn}$ & 3.23 & & 0 & & & 0 \\
\hline & & 3.22 & & 0.20 & & & 0.40 \\
\hline & & 3.23 & 0 & 0.40 & 0.26 & 0 & 0.20 \\
\hline $\mathrm{CdMnSe}_{(\text {in } Q)}$ & $\mathrm{Se}$ & 2.18 & 0 & 1.33 & 0.54 & 0 & 0 \\
\hline $\mathrm{CdSeTe}_{(\text {in } Q)}$ & $\mathrm{Cd}$ & 2.38 & 0 & 1.33 & 0.54 & 0 & 0 \\
\hline $\mathrm{CdMnTe}_{\text {(in } Q)}$ & $\mathrm{Te}$ & 3.23 & 0 & 0 & 0.26 & 0 & 0 \\
\hline $\mathrm{CdMnTe}_{\text {(as } T \text { ) }}$ & & 0.68 & 1.33 & 0 & 0.68 & 0.67 & 0 \\
\hline
\end{tabular}

Quaternary sphalerite crystals have two distinct system structures - pseudo-Q and truly-Q - and require distinct ad hoc theoretical treatments. The topological structure of the ideal, canonical crystal (i.e., with no point defects or impurities) attributes respectively 28 and 30 basic phonon frequencies. In a real crystal, due to defects and impurities the number of frequencies further increases (see, for instance, $[39,40])$. We discussed EXAFS and phonon spectra of pseudo-Q alloys (GaInAsSb [29] (Fig. 3 and Table 3) and our data of CdMnSeTe [30] (Fig. 4 and Table 4)) and the phonon spectra of truly-Q ZnCdHgTe. Three of the four Q22 CdMnSeTe samples investigated by EXAFS, have been re-examined with FIR reflectivity [6], and the main results are summarized below.

A pseudo-Q zincblende system responds as a linear superposition of the contributions of binary and ternary elemental tetrahedra of the four ternary components, as shown by the analysis of both EXAFS and FIR phonon spectra. Thus, the strained tetrahedron model, designed to interpret ternary tetrahedron coordinated systems, successfully interprets $\mathrm{A}_{1-x} \mathrm{~B}_{x} \mathrm{Y}_{y} \mathrm{Z}_{1-y}$ systems. Most semiconductors exhibit SOPs, as experimentally confirmed yielding quantitative SOP coefficient values reliably using different models. The strained tetrahedron model gives a good agreement for both EXAFS data [1,2] and FIR spectra [4,5] of sphalerite ternary
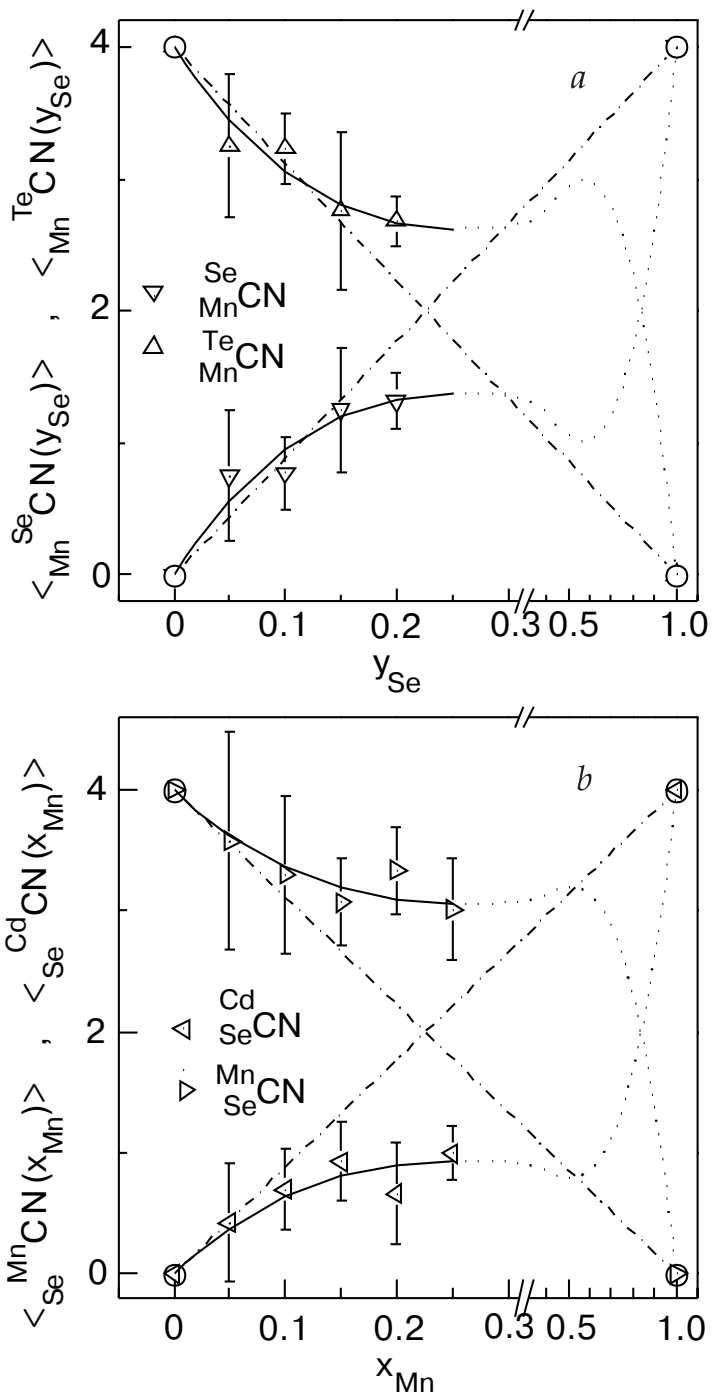

Fig. 4. Analysis of $\mathrm{Cd}_{1-x} \mathrm{Mn}_{x} \mathrm{Se}_{y} \mathrm{Te}_{1-y}$ EXAFS $\langle\mathrm{CN}\rangle$ data [32]. Experimental points: triangles pointing $(a)$ down: $\mathrm{Se} \mathrm{CN}$, up: ${ }_{\mathrm{Mn}}^{\mathrm{Te}} \mathrm{CN},(b)$ left: $\mathrm{Se}_{\mathrm{Ce}} \mathrm{CN}$, right: $\mathrm{Se}_{\mathrm{CN}} \mathrm{CN}$ derived $\langle\mathrm{CN}\rangle$ curves, within the sphalerite range (solid), (dotted) beyond the sphalerite range. Random limit (dash dotted).

$\mathrm{A}_{1-x} \mathrm{~B}_{x} \mathrm{Z}$ and $\mathrm{AY}_{y} \mathrm{Z}_{1-y}$, and now to the Q22 $\mathrm{A}_{1-x} \mathrm{~B}_{x} \mathrm{Y}_{y} \mathrm{Z}_{1-y}$ systems [6]. It also successfully interprets EXAFS data of intermetallic $\mathrm{M}_{3}\left(\mathrm{XX}^{\prime}\right)$ [3] systems, and within certain limitations may do so for some wurzite crystalline structures [2], returning SOP coefficient values. As a ternary is progressively diluted within the Q22, the evolution of the SOP-coefficients is a valuable index of the thermodynamic evolution of the system. Indeed, the heterogeneous presence of competing ions in the NNN shell profoundly modifies the SOPs with respect to the corresponding pure ternary (which has a perfectly homogeneous NNN shell composition), and the system is affected by the site occupation competition in both the cation and the anion sublattices, i.e., all shells, hence, SOPs conditioned by relative concentrations. Thus in contrast with SOPs of a pure ternary 
for $\operatorname{GaInAs}_{(\text {as T) }}$ in which the NNN ions around any cation are all As-anions, in $\mathrm{Ga}_{x} \mathrm{In}_{1-x} \mathrm{As}_{0.05} \mathrm{Sb}_{0.95}$, $\operatorname{GaInAs}_{\text {(in Q) }}$ they are almost all Sb-anions. In Q22 and in ternary systems, line shapes and intensities are determined, to a first approximation, by the cation-anion dipole pair, and are unaffected by the center-vertex position of the dipole within the tetrahedron configuration. Indeed, observing the normalized variance $s^{2}$ values of successive best-fit results (Table 3 [6]) confirms our assumption that the two phonons emitted by a dipole $Z^{\mathrm{A}}$ from the ternary $\mathrm{A}_{x} \mathrm{~B}_{1-x} \mathrm{Z}$ and by $\mathrm{A}^{Z}$ from the complementary $\mathrm{AY}_{y} \mathrm{Z}_{1-y}$, are substantially equivalent.

In contrast with Q22, the Q31 and Q13 systems have SOP coefficients invariant with relative contents values. Indeed, a truly-Q system, Q31 or Q13, is characterised by three ions competing for site occupation in a shell bounded on both sides by shells with homogeneous mono-ions of the complementary sublattice.

Many semiconductors exhibit SOPs with extreme values. Such a behavior indicates that the ternary filling of one (sometimes two) of the three elemental tetrahedron configuration(s) is almost negligible. This may be explained by a thermodynamic affinity of cat- ion-anion pair components in ternary or quaternary systems. A wide group of semiconductors is characterized by missing elementary configurations, a behavior that is still not understood.

Noteworthy, Q22 FIR spectra exhibit a trend versus temperature, that could be correlated to the EXAFS analysis of these materials at different temperatures and in particular to the behavior of the Debye-Waller parameters.

Our analysis shows that one of the major consequences of the difference among SOPs in truly-Q and pseudo-Q is due to their structural difference. In fact as the relative ion contents vary, in a truly- $Q$ the 12 SOP coefficient values remain constant, while in a pseudo-Q system, i.e., a mixture of ternaries, the 12 SOP values are functions of the relative contents.

Work is in progress to determine from available FIR-spectra [7] the values of the twelve SOP-coefficients for the truly-Q ZnCdHgTe similarly to the work performed in the ternary GaAsP [4,5].

Part of this work was supported by EU TARI-project contract HPRI-CT-1999-00088.

\section{Appendix (vademecum of Sphalerite system equations)}

We here reassume the equations based on the assumptions of the statistical strained tetrahedron model as derived in extenso in manuscripts [1-6]. The corresponding parameters are indicated.

\section{Appendix 1. SOP $W$ - and C-coefficients $[1,6]$}

All probability coefficients being nonnegative, restricts SOP $W$-coefficients values.

Preferences affect configuration probability $C$-coefficients as follows

\begin{tabular}{|c|c|c|}
\hline \multicolumn{3}{|l|}{ System } \\
\hline ternary [1] & & $\left\{0 \leq W_{k} \leq 4 / k\right\}_{k=13}$ \\
\hline $3\left\{W_{k}\right\}_{k=1.3}$ parameters & with & $0 \leq\left\{C_{k}=\min \left[W_{k}, 1,\left(4-k W_{k}\right) /(4-k)\right]\right\}_{k=1.3} \leq 1$ \\
\hline pseudo quaternary [6] & & $\left\{0 \leq_{c} W_{k} \leq 4 / k\right\}_{k=1.3 ; c=\mathrm{A}, \mathrm{B}, \mathrm{Y}, \mathrm{Z}}$ \\
\hline $12\left\{_{c} W_{k}\right\}_{k=1.3 ; c=\mathrm{A}, \mathrm{B}, \mathrm{Y}, \mathrm{Z}}$ parameters & with & $0 \leq\left\{C_{c}=\min \left[{ }_{c} W_{k}, 1,\left(4-k_{c} W_{k}\right) /(4-k)\right]\right\}_{k=1,3 ; c=\mathrm{A}, \mathrm{B}, \mathrm{Y}, \mathrm{Z}} \leq 1$ \\
\hline truly quaternary & & $0 \leq\left\{(k+j) W_{k j}\right\}_{k=0.3 ; j=0.3-k} \leq 4,0 \leq\left\{k W_{k,(4-k)}\right\}_{k=1.3} \leq 4$ \\
\hline and for pure $Q-$ configurations & & and $0 \leq W_{2.1} \leq 4 / 3,0 \leq W_{1.2} \leq 4 / 3,0 \leq W_{1.1} \leq 2$ \\
\hline $12\left\{W_{k j}\right\}_{k=0.3 ; j=0.3-k}$ & with & $0 \leq C_{k j}=\min \left\{W_{k j}, 1,\left[4-(k+j) W_{k j}\right] /(4-k-j)\right\} \leq 1$ \\
\hline
\end{tabular}


Appendix 2. EXAFS - coordination numbers

equations defining the average $N N$ coordination numbers

Ternary

$$
\left.\mathrm{A}_{1-x} \mathrm{~B}_{x} \mathrm{Z} \text { (or } \mathrm{AY}_{y} \mathrm{Z}_{1-y}\right)
$$

Parameters 3: $\left\{W_{k}\right\}_{k=1.3}$

$<{ }_{\mathrm{A}}^{\mathrm{Z}} \mathrm{CN}(x)>=<_{\mathrm{B}}{ }^{\mathrm{Z}} \mathrm{CN}(x)>=4$
$<{ }_{\mathrm{Z}}^{\mathrm{B}} \mathrm{CN}(x)>=\Sigma_{k=0.3} \Sigma_{j=1.4-k}\left[\left(j W_{k j}\right) \mathrm{p}_{k j}(x)\right]$
$<_{\mathrm{Z}}{ }^{\mathrm{A}} \mathrm{CN}(x)>=\Sigma_{k=1.4} \Sigma_{j=0.4-k}\left[\left(k W_{k j}\right) \mathrm{p}_{k j}(x)\right]=4-<_{\mathrm{Z}}{ }^{\mathrm{B}} \mathrm{CN}(x)>$

\section{Pseudo quaternary}

$$
\mathrm{A}_{1-x} \mathrm{~B}_{\boldsymbol{x}} \mathrm{Y}_{y} \mathrm{Z}_{1-y}
$$

\begin{tabular}{|c|c|}
\hline${ }^{\mathrm{NN}}$ dipole $<\mathrm{CN}(x, y)>$ & $\begin{array}{l}\text { Pseudo quaternary } \\
\mathrm{A}_{1-x} \mathrm{~B}_{x} \mathrm{Y}_{y} \mathrm{Z}_{1-y} \\
\end{array}$ \\
\hline $\begin{aligned}{ }^{\mathrm{AZ}} & <{ }_{\mathrm{A}}^{\mathrm{Z}} \mathrm{CN}(y)>= \\
& <{ }_{\mathrm{Z}}^{\mathrm{A}} \mathrm{CN}(x)>= \\
\mathrm{BZ} & <{ }_{\mathrm{B}}^{\mathrm{Z}} \mathrm{CN}(y)>= \\
& <{ }_{\mathrm{Z}}{ }^{\mathrm{B}} \mathrm{CN}(x)>= \\
\mathrm{AY} & <{ }_{\mathrm{A}}{ }^{\mathrm{Y}} \mathrm{CN}(y)>= \\
& <{ }_{\mathrm{Y}}^{\mathrm{A}} \mathrm{CN}(x)>= \\
\mathrm{BY} & <{ }_{\mathrm{B}}{ }^{\mathrm{Y}} \mathrm{CN}(y)>= \\
& <{ }_{\mathrm{Y}}^{\mathrm{B}} \mathrm{CN}(x)>=\end{aligned}$ & $\begin{array}{l}\left.\left.W_{k}\right) \mathrm{p}_{k}{ }^{[4]}(y)\right]=4-<{ }_{\mathrm{A}}{ }^{\mathrm{Y}} \mathrm{CN}(y)> \\
\left.\left.W_{k}\right) \mathrm{p}_{k}{ }^{[4]}(x)\right]=4-<_{\mathrm{Z}}{ }^{\mathrm{B}} \mathrm{CN}(x)> \\
\left.\left.W_{k}\right) \mathrm{p}_{k}{ }^{[4]}(y)\right]=4-<_{\mathrm{B}}{ }^{\mathrm{Y}} \mathrm{CN}(y)> \\
\left.\mathrm{p}_{k}{ }^{[4]}(x)\right]=4-<{ }_{\mathrm{Z}}{ }^{\mathrm{A}} \mathrm{CN}(x)> \\
\left.\mathrm{p}_{k}{ }^{[4]}(y)\right]=4-<{ }_{\mathrm{A}}{ }^{\mathrm{Z}} \mathrm{CN}(y)> \\
\left.\left.{ }{ }{ }_{k}\right) \mathrm{p}_{k}{ }^{[4]}(x)\right]=4-<_{\mathrm{Y}}{ }^{\mathrm{B}} \mathrm{CN}(x)> \\
\left.\mathrm{p}_{k}{ }^{[4]}(y)\right]=4-<_{\mathrm{B}}{ }^{\mathrm{Z}} \mathrm{CN}(y)> \\
\left.\mathrm{p}_{k}{ }^{[4]}(x)\right]=4-<_{\mathrm{Y}}{ }^{\mathrm{A}} \mathrm{CN}(\mathrm{x})>\end{array}$ \\
\hline
\end{tabular}

Parameters 12: $\left\{{ }_{c} W_{k}\right\}_{k=1.3 ; c=\mathrm{A}, \mathrm{B}, \mathrm{Y}, \mathrm{Z}}$

\section{Truly quaternary}

$$
\mathrm{A}_{x} \mathrm{~B}_{x^{\prime}} \mathrm{C}_{1-x-x^{\prime}} \mathrm{Z} \text { or } \mathrm{AX}_{y} \mathrm{Y}_{y^{\prime}} \mathrm{Z}_{1-y-y^{\prime}}
$$

Parameters 12: $\left\{W_{k j}\right\}$

$$
\begin{aligned}
<_{\mathrm{A}}{ }^{\mathrm{Z}} \mathrm{CN}\left(x, x^{\prime}\right)> & =<_{\mathrm{B}}{ }^{\mathrm{Z}} \mathrm{CN}\left(x, x^{\prime}\right)>=<_{\mathrm{C}}{ }^{\mathrm{Z}} \mathrm{CN}\left(x, x^{\prime}\right)>=4 \\
<{ }_{\mathrm{Z}}{ }^{\mathrm{A}} \mathrm{CN}\left(x, x^{\prime}\right)> & =\Sigma_{k=1.4} \sum_{j=0.4-k}\left[\left(k W_{k j}\right) p_{k j}\left(x, x^{\prime}\right)\right] \\
<_{\mathrm{Z}}{ }^{\mathrm{B}} \mathrm{CN}\left(x, x^{\prime}\right)> & =\Sigma_{k=0.3} \Sigma_{j=1.4-k}\left[\left(j W_{k j}\right) p_{k j}\left(x, x^{\prime}\right)\right] \\
<_{\mathrm{Z}}{ }^{\mathrm{C}} \mathrm{CN}\left(x, x^{\prime}\right)> & =\Sigma_{k=0.3} \Sigma_{j=0.3-k}\left[(4-k-j) W_{k j} p_{k j}\left(x, x^{\prime}\right)\right]= \\
& =4-{ }_{\mathrm{Z}}{ }^{\mathrm{A}} \mathrm{CN}\left(x, x^{\prime}\right)>-<_{\mathrm{Z}}{ }^{\mathrm{B}} \mathrm{CN}\left(x, x^{\prime}\right)>
\end{aligned}
$$

Appendix 3. Tetrahedron configuration probabilities

\begin{tabular}{|c|c|}
\hline$\left\{P_{k}(x)=C_{k} p_{k}^{[4]}\right\}_{k=1.3}$ & of ternary $T_{k}$ \\
\hline$P_{0}(x)=\left\{p_{0}^{[4]}(x)+\Sigma_{k=1.3}\left[\max \left(0,1-W_{k}\right) p_{k}^{[4]}(x)\right]\right\}$ & of binary $A Z$ configuration $T_{0}$ \\
\hline$P_{4}(x)=\left\{p_{4}^{[4]}(x)+\Sigma_{k=1.3}\left[\max \left(0, k\left(W_{k}-1\right) /(4-k)\right) p_{k}(x)\right]\right\}$ & of binary $B Z$ configuration $T_{4}$ \\
\hline
\end{tabular}

$$
\left(P_{\text {ternary }}: P_{k}(x) ; P_{\text {pseudoQ }}: P_{k}(x, y) ; P_{\text {truly } Q}: P_{k j}(x, y)\right)
$$

\section{Ternary}

$$
\left.\mathrm{A}_{1-x} \mathrm{~B}_{x} \mathrm{Z} \text { (or } \mathrm{AY}_{y} \mathrm{Z}_{1-y}\right)
$$

Non binary configurations: $3\left\{T_{k}\right\}_{k=1.3}$.Parameters 3: $\left\{W_{k}\right\}_{k=1.3}$

Stoichiometry preference shifts:

$W_{k}<1$ enhances binary AZ populations, while $W_{k}>1$ that of binary BZ, i.e. 


\section{Pseudo quaternary}

$$
\mathrm{A}_{1-x} \mathrm{~B}_{x} \mathrm{Y}_{y} \mathrm{Z}_{1-y}
$$

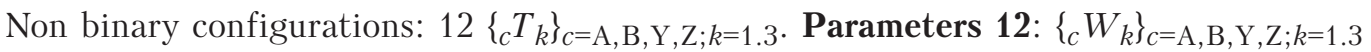

Stoichiometry preference shifts to binary:
AZ for ${ }_{\mathrm{Z}} W_{k}<1$ and for ${ }_{\mathrm{A}} W_{k}<1$,
BZ for ${ }_{\mathrm{Z}} W_{k}>1$ and ${ }_{\mathrm{B}} W_{k}<1$,
AY for ${ }_{\mathrm{Y}} W_{k}<1$ and ${ }_{\mathrm{A}} W_{k}>1$,
BY for ${ }_{\mathrm{B}} W_{k}>1$ and ${ }_{\mathrm{Y}} W_{k}>1$.

Let $\left\{{ }_{c} \mathrm{v}(x, y)\right\}_{c=\mathrm{A}, \mathrm{B}, \mathrm{Y}, \mathrm{Z}}:=x$ for $c=\mathrm{Y}$ or $c=\mathrm{Z}$, and $=y$ for $c=\mathrm{A}$ or $c=\mathrm{B}$, and $\left.\left\{\eta_{c}(x, y)\right\}_{c=\mathrm{A}, \mathrm{B}, \mathrm{Y}, \mathrm{Z} ; k=1.3}\right)=\{(1-\mathrm{x}) / 2, \mathrm{x} / 2, y / 2,(1-y) / 2\}$, with $\Sigma_{c=\mathrm{A}, \mathrm{B}, \mathrm{Y}, \mathrm{Z}} \eta_{c}(x, y) \equiv 1$

\begin{tabular}{||lc||}
\hline$\left.{ }_{c} P_{k}(x, y)=\eta_{c}(x, y){ }_{c} C_{k} p_{k}{ }^{[4]}\left[{ }_{c} \mathrm{v}(x, y)\right]\right\}_{k=1.3}$ & of ternary ${ }_{c} T_{k}$ \\
${ }_{c} P_{0}(x, y)=\eta_{c}(x, y)\left\{p_{0}{ }^{[4]}(x)+\Sigma_{k=1.3}\left[\max \left(0,1-{ }_{c} W_{k}\right) p_{k}{ }^{[4]}(x)\right]\right\}$ & of binary AZ configuration ${ }_{c} T_{0}$ \\
$c P_{4}(x, y)=\eta_{c}(x, y)\left\{p_{4}{ }^{[4]}(x)+\Sigma_{k=1.3}\left[\max \left(0, k\left({ }_{c} W_{k}-1\right) /(4-k)\right) p_{k}{ }^{[4]}(x)\right]\right\}$ & of binary BZ configuration ${ }_{c} T_{4}$ \\
\hline
\end{tabular}

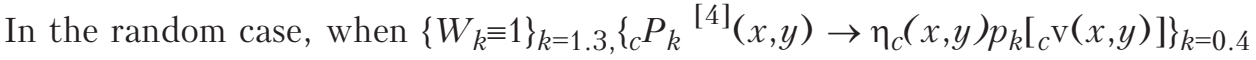

Truly quaternary

$$
\mathrm{A}_{\boldsymbol{x}} \mathrm{B}_{\boldsymbol{x}^{\prime}} \mathrm{C}_{\mathbf{1}-\boldsymbol{x}-\boldsymbol{x}^{\prime}} \mathrm{Z} \text { or } \mathrm{AX}_{\boldsymbol{y}} \mathrm{Y}_{\boldsymbol{y}^{\prime}} \mathrm{Z}_{\mathbf{1}-\boldsymbol{y}-\boldsymbol{y}^{\prime}}
$$

\begin{tabular}{|c|c|}
\hline$\left\{P_{k j}\left(x, x^{\prime}\right)=C_{k j} p_{k j}\left(x, x^{\prime}\right)\right\}_{k=0.4 ; j=0,(4-k)}$ & for non binary \\
\hline \multicolumn{2}{|l|}{$\delta P_{40}\left(x, x^{\prime}\right)=\Sigma_{k=1.3} \Sigma_{j=0.3-k}\left[\max \left(0,(k+j)\left(W_{k j}-1\right) /(4-k-j)\right) p_{k j}\left(x, x^{\prime}\right)\right]$} \\
\hline$+\Sigma_{k=1.3}\left[\max \left(0, k\left(W_{k,(4-k)}-1\right) /(4-k)\right) p_{k,(4-k)}\left(x, x^{\prime}\right)\right]$ & for binary AZ \\
\hline \multicolumn{2}{|l|}{$\delta P_{04}\left(x, x^{\prime}\right)=\Sigma_{k=0.3} \Sigma_{j=1.3-k}\left[\max \left(0,(k+j)\left(W_{k j}-1\right) /(4-k-j)\right) p_{k j}\left(x, x^{\prime}\right)\right]$} \\
\hline$+\Sigma_{k=1.3}\left[\max \left(0,1-W_{k,(4-k)}\right) p_{k,(4-k)}\left(x, x^{\prime}\right)\right]$ & for binary BZ \\
\hline$\delta P_{00}\left(x, x^{\prime}\right)=\Sigma_{k=0.3} \Sigma_{j=0.3-k}\left[\max \left(0,1-W_{k j}\right) p_{k j}\left(x, x^{\prime}\right)\right]$ & $\begin{array}{c}\text { for binary } \mathrm{CZ} \\
\text { (4) }\end{array}$ \\
\hline \multicolumn{2}{|l|}{ with } \\
\hline $\begin{array}{l}\Sigma_{k=0.4} \Sigma_{j=0.4-k}\left\{P_{k j}\left(x, x^{\prime}\right)\right\}+\delta P_{40}\left(x, x^{\prime}\right)+\delta P_{04}\left(x, x^{\prime}\right)+\delta P_{00}\left(x, x^{\prime}\right)= \\
\quad=\Sigma_{k=0.4} \Sigma_{j=0.4-k}\left\{p_{k j}\left(x, x^{\prime}\right)\right\} \equiv 1\end{array}$ & (5) \\
\hline$\left.\Sigma_{k=0.4 ; j=0.4-k} k^{*} p_{k j}\left(x, x^{\prime}\right)\right\} \equiv 4 \mathrm{x}$ & \\
\hline$\left.\Sigma_{k=0.4 ; j=0.4-k} j^{*} p_{k j}\left(x, x^{\prime}\right)\right\} \equiv 4 x^{\prime}$ & (6) \\
\hline$\left.\Sigma_{k=0.4 ; j=0.4-k} k^{*} p_{k j}\left(x, x^{\prime}\right)\right\} \equiv 4\left(1-\mathrm{x}-x^{\prime}\right)$ & \\
\hline In the random case, when $\left\{W_{k j} \equiv 1\right\}_{k=0.4 ; j=0.4-k},\left\{P_{k j}\left(x, x^{\prime}\right) \rightarrow p_{k j}\left(x, x^{\prime}\right)\right\}_{k=0.4 ; j=0.4-k}$ & \\
\hline
\end{tabular}

Non binary configurations: $12\left\{\mathrm{~T}_{k j}\right\}$. Parameters 12: $\left\{W_{k j}\right\}$

Appendix 4. EXAFS - average NN inter - ion distances $<_{Z}{ }^{\text {vertex }} d\left(x, x^{\prime}\right)>$

(the binary distance values are from the literature)

Ternary

$$
\left.\mathrm{A}_{1-x} \mathrm{~B}_{x} \mathrm{Z} \text { (or } \mathrm{AY}_{y} \mathrm{Z}_{1-y}\right)
$$

NN equations: 2. Parameters 9: 6 distance $\left\{{ }^{\mathrm{AZ}} d_{k},{ }^{\mathrm{BZ}} d_{k}\right\}_{k=1.3}+3\left\{W_{k}\right\}_{k=1.3}$

$$
\begin{array}{ll}
<_{\mathrm{Z}}{ }^{\mathrm{B}} d(x)>= & \left\{\Sigma_{k=1.4}\left[\left(k C_{k}\right){ }^{\mathrm{BZ}} d_{k}+4 \operatorname{Max}\left(0, W_{k}-1\right){ }^{\mathrm{BZ}} d_{4}\right] p_{k}^{[4]}(x)\right\} \\
& /\left\{\Sigma_{k=1.4}\left[\left(k C_{k}\right)+4 \operatorname{Max}\left(0, W_{k}-1\right)\right] p^{[4]}(x)\right\} \\
& \left\{\Sigma_{k=0.3}\left[\left(4-k C_{k}\right){ }^{\mathrm{AZ}} d_{k}+4 \operatorname{Max}\left(0,1-W_{k}\right){ }^{\mathrm{AZ}} d_{0}\right] p^{[4]}(x)\right\} \\
& /\left\{\Sigma_{k=0.3}\left[\left(4-k C_{k}\right)+4 \operatorname{Max}\left(0,1-W_{k}\right)\right] p^{\mathrm{A}} d(x)>=\quad{ }_{k}(x)\right\}
\end{array}
$$


Pseudo quaternary

$$
\mathrm{A}_{1-x} \mathrm{~B}_{\boldsymbol{x}} \mathrm{Y}_{y} \mathrm{Z}_{1-y}
$$

NN equations: 4. Parameters 36: 24 distances $\left\{{ }_{c}{ }_{c}^{\mathrm{cv}} d_{k}\right\}_{k=1.3 ; c=\mathrm{A}, \mathrm{B}, \mathrm{Y}, \mathrm{Z} ; \mathrm{v}=\mathrm{v} 1, \mathrm{v} 2}+12\left\{{ }_{c} W_{k}\right\}_{c=\mathrm{A}, \mathrm{B}, \mathrm{Y}, \mathrm{Z} ; k=1.3}$

$$
\begin{aligned}
& <_{\mathrm{A}}^{\mathrm{Z}} d(x, y)>=\left\{(1-x) \Sigma_{k=0.3}\left\{{ }_{A}^{Z} d_{k}\left(4-k_{\mathrm{A}} C_{k}\right)+4{ }_{A}^{A Z} d_{0} \max \left(0,1-{ }_{\mathrm{A}} w_{k}\right)+4{ }_{A}^{A Z} d_{4} \max \left[0,\left(k_{\mathrm{A}} W_{k}-1\right) /(4-k)\right]\right\} p_{k}^{[4]}(y)\right\} / \\
& /\left\{(1-x) \Sigma_{k=0.3}\left\{\left(4-k_{\mathrm{A}} C_{k}\right)+4 \max \left(0,1-{ }_{\mathrm{A}} W_{k}\right)+4 \max \left[0,\left(k_{\mathrm{A}} W_{k}-1\right) /(4-k)\right]\right\} p_{k}{ }^{[4]}(y)\right\} \\
& <_{\mathrm{B}}^{\mathrm{Z}} d(x, y)>=\quad\left\{x \Sigma_{k=1.4}\left\{{ }_{\mathrm{B}}^{B Z} d_{k}\left(4-k_{\mathrm{B}} C_{k}\right)+4{ }_{\mathrm{B}}^{B Z} d_{4} \max \left(0,1-{ }_{\mathrm{B}} W_{k}\right)+4{ }_{\mathrm{B}}^{A Z} d_{4} \max \left[0,\left(k_{\mathrm{B}} W_{k}-1\right) /(4-k)\right]\right\} p_{k}{ }^{[4]}(y)\right\} / \\
& /\left\{x \Sigma_{k=1.4}\left\{\left(4-k{ }_{\mathrm{B}} C_{k}\right)+4 \max \left(0,1-{ }_{\mathrm{B}} W_{k}\right)+4 \max \left[0,\left(k_{\mathrm{B}} W_{k}-1\right) /(4-k)\right]\right\} p_{k}{ }^{[4]}(y)\right\} \\
& <_{\mathrm{Y}}{ }^{\mathrm{A}} d(x, y)>=\quad\left\{y \Sigma_{k=0.3}\left\{\mathrm{Z}_{\mathrm{Z}}^{\mathrm{AY}} d_{k}\left(4-k_{\mathrm{Z}} C_{k}\right)+4 \underset{\mathrm{Z}}{\mathrm{AY}} d_{0} \max \left(0,1-\mathrm{Z}_{k} w_{k}\right)+4 \underset{\mathrm{Z}}{\mathrm{AY}} d_{4} \max \left[0,\left(k_{\mathrm{Z}} W_{k}-1\right) /(4-k)\right]\right\} p_{k}{ }^{[4]}(x)\right\} \\
& \left\{y \Sigma_{k=0.3}\left\{\left(4-k_{\mathrm{Z}} C_{k}\right)+4 \max \left(0,1-{ }_{\mathrm{Z}} W_{k}\right)+4 \max \left[0,\left(k_{\mathrm{Z}} W_{k}-1\right) /(4-k)\right]\right\} p_{k}{ }^{[4]}(x)\right\} \\
& <_{\mathrm{Z}}^{\mathrm{B}} d(x, y)>=\quad\left\{y \Sigma_{k=1.4}\left\{\mathrm{~B}_{\mathrm{Z}}^{\mathrm{BY}} d_{k}{ }_{\mathrm{Z}} C_{k}+4 \underset{\mathrm{Z}}{\mathrm{BY}} d_{4} \max \left(0,1-{ }_{\mathrm{Z}} W_{k}\right)+4{ }_{\mathrm{Z}}^{\mathrm{BY}} d_{4} \max \left[0,\left(k_{\mathrm{Z}} W_{k}-1\right) /(4-k)\right]\right\} p_{k}^{[4]}(x)\right\} \\
& /\left\{y \Sigma_{k=1.4}\left\{k_{Z} C_{k}+4 \max \left(0,1-{ }_{Z} W_{k}\right)+4 \max \left[0,\left(k_{Z} W_{k}-1\right) /(4-k)\right]\right\} p_{k}{ }^{[4]}(x)\right\}
\end{aligned}
$$

Truly quaternary

$$
\mathrm{A}_{x} \mathrm{~B}_{x^{\prime}} \mathrm{C}_{1-x-x^{\prime}} \mathrm{Z} \text { or } \mathrm{AX}_{y} \mathrm{Y}_{y^{\prime}} \mathrm{Z}_{1-y-y^{\prime}}
$$

NN equations: 3. Parameters 21: 9 distance $\left\{{ }^{\mathrm{vZ}} d_{k}\right\}_{k=1.3 ; \mathrm{v}=\mathrm{A}, \mathrm{B}, \mathrm{C}}+12\left\{W_{k j}\right\}$

$$
\begin{aligned}
& <_{\mathrm{Z}}{ }^{\mathrm{A}} d\left(x, x^{\prime}\right)>=\left\{\Sigma_{k=1.4} \Sigma_{j=0.4-k}\left[_{\mathrm{Z}}{ }^{\mathrm{A}} d_{k j} k P_{k j}\left(x, x^{\prime}\right)\right]+4{ }_{\mathrm{Z}}{ }^{\mathrm{A}} d_{40} \delta P_{40}\left(x, x^{\prime}\right)\right\} / 4 \mathrm{x} \\
& \left.<_{\mathrm{Z}}{ }^{\mathrm{B}} d\left(x, x^{\prime}\right)>=\left\{\Sigma_{k=0.3} \Sigma_{j=1.4-k}{ }_{\mathrm{Z}}{ }_{\mathrm{Z}}^{\mathrm{B}} d_{k j} j P_{k j}\left(x, x^{\prime}\right)\right]+4{ }_{\mathrm{Z}}{ }^{\mathrm{B}} d_{04}{ }^{\delta} P_{04}\left(x, x^{\prime}\right)\right\} / 4 x^{\prime} \\
& \left.<_{\mathrm{Z}}{ }^{\mathrm{C}} d\left(x, x^{\prime}\right)>=\left\{\Sigma_{k=0.3} \Sigma_{j=0.3-k} \mathrm{I}_{\mathrm{Z}}{ }^{\mathrm{C}} d_{k j}(4-k-j) P_{k j}\left(x, x^{\prime}\right)\right]+4{ }_{\mathrm{Z}}{ }^{\mathrm{C}} d_{00} \delta P_{00}\left(x, x^{\prime}\right)\right\} / 4\left(1-\mathrm{x}-x^{\prime}\right)
\end{aligned}
$$

\section{Appendix 5. FIR}

Recall that by axioms 6' ad 7': ${ }^{\mathrm{AZ}} \Gamma=\left\{{ }^{\mathrm{AZ}} \Gamma_{k}={ }^{\mathrm{AZ}} \Gamma_{k j}\right\},{ }^{\mathrm{BZ}} \Gamma=\left\{{ }^{\mathrm{BZ}} \Gamma_{k}={ }^{\mathrm{BZ}} \Gamma_{k j}\right\},{ }^{\mathrm{CZ}} \Gamma=\left\{{ }^{\mathrm{CZ}} \Gamma_{k}={ }^{\mathrm{CZ}} \Gamma_{k j}\right\}$, and ${ }^{\mathrm{AZ}} s=\left\{{ }^{\mathrm{AZ}} s_{k}={ }^{\mathrm{AZ}} s_{k j}\right\},{ }^{\mathrm{BZ}}{ }_{s}=\left\{{ }^{\mathrm{BZ}} s_{k}={ }^{\mathrm{BZ}} s_{k j}\right\},{ }^{\mathrm{CZ}}{ }_{s}=\left\{{ }^{\mathrm{CZ}} s_{k}={ }^{\mathrm{CZ}} s_{k j}\right\}$ for all $k=0.4$ and $j=0.4$

Ternary

$$
\mathrm{A}_{1-x} \mathrm{~B}_{x} \mathrm{Z}\left(\text { or } \mathrm{AY}_{y} \mathrm{Z}_{1-y}\right)
$$

Parameters 15: $\left.8\left\{{ }^{\mathrm{AZ}} \omega_{k}\right\}_{k=0.3},\left\{{ }^{\mathrm{BZ}} \omega_{k}\right\}_{k=1.4}\right\}+3\left\{W_{k}\right\}_{k=1.3}+2\left\{{ }^{\mathrm{AZ}} \Gamma,{ }^{\mathrm{BZ}} \Gamma\right\}+2\left\{{ }^{\mathrm{AZ}}{ }_{s}{ }^{\mathrm{BZ}}{ }_{s}\right\}$

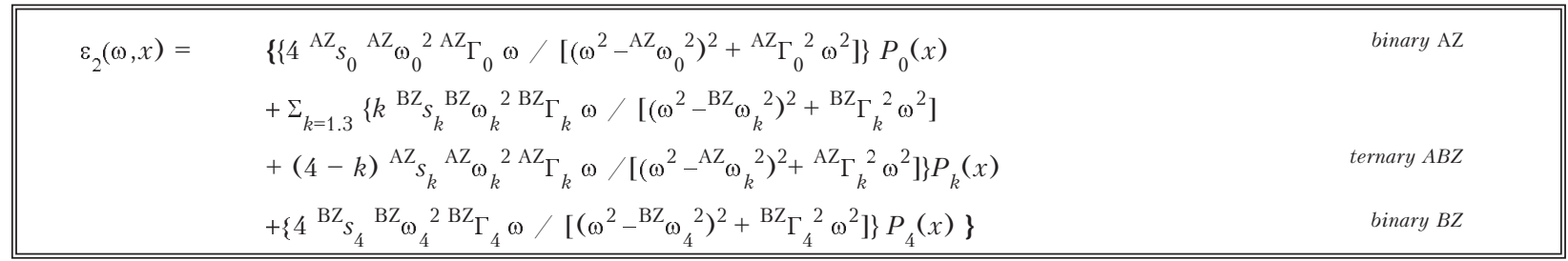

\section{Pseudo quaternary}

$$
\mathrm{A}_{1-x} \mathrm{~B}_{x} \mathrm{Y}_{y} \mathrm{Z}_{1-y}
$$

Parameters 52: $32\left\{{ }^{i j}{ }_{c} \omega_{k}\right\}+12\left\{{ }_{c} W_{k}\right\}_{c=\mathrm{A}, \mathrm{B}, \mathrm{Y}, \mathrm{Z} ; k=1.3}+4\left\{{ }^{\mathrm{AZ}} \Gamma,{ }^{\mathrm{BZ}} \Gamma,{ }^{\mathrm{AY}} \Gamma,{ }^{\mathrm{BY}} \Gamma\right\}+4\left\{{ }_{\mathrm{sZ}},{ }^{\mathrm{BY}} \mathrm{s},{ }_{\mathrm{S}}{ }^{\mathrm{AZ}}{ }_{\mathrm{s}}\right\}$ 


\begin{tabular}{|c|c|c|c|}
\hline$\varepsilon_{2}\left(\omega, \mathrm{x}, x^{\prime}\right)$ & 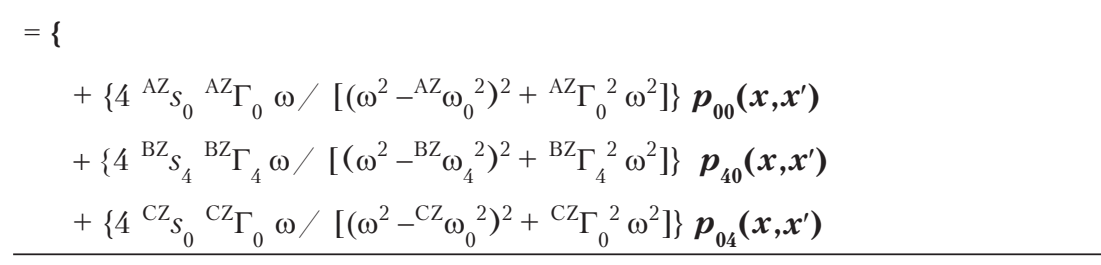 & \begin{tabular}{|l} 
binary $\mathrm{AZ}$ \\
binary $\mathrm{BZ}$ \\
binary $\mathrm{CZ}$
\end{tabular} & $\begin{array}{r}k_{\mathrm{A}_{-}} k_{\mathrm{B}} \\
4,0 \\
0.4 \\
0,0\end{array}$ \\
\hline & $\begin{aligned} \Sigma_{k=1.3} & \left\{k{ }^{\mathrm{ABZ}} C_{k}{ }^{\mathrm{BZ}} S_{k}{ }^{\mathrm{BZ}} \Gamma_{k} \omega /\left[\left(\omega^{2}-{ }^{\mathrm{BZ}} \omega_{k}{ }^{2}\right)^{2}+{ }^{\mathrm{BZ}} \Gamma_{k}{ }^{2} \omega^{2}\right]\right. \\
& +\left(4-k{ }^{\mathrm{ABZ}} C_{k}\right){ }^{\mathrm{AZ}}{ }_{k}{ }^{\mathrm{AZ}} \Gamma_{k} \omega /\left[\left(\omega^{2}-{ }^{\mathrm{AZ}} \omega_{k}{ }^{2}\right)^{2}+{ }^{\mathrm{AZ}} \Gamma_{k}{ }^{2} \omega^{2}\right] \\
& +4 \operatorname{Max}\left(0,{ }^{\mathrm{ABZ}} W_{k}-1\right){ }^{\mathrm{BZ}} S_{4}{ }^{\mathrm{BZ}} \Gamma_{4} \omega /\left[\left(\omega^{2}-{ }^{\mathrm{BZ}} \omega_{4}{ }^{2}\right)^{2}+{ }^{\mathrm{BZ}} \Gamma_{4}{ }^{2} \omega^{2}\right] \\
& \left.+4 \operatorname{Max}\left(0,1-{ }^{\mathrm{ABZ}} W_{k}\right){ }^{\mathrm{AZ}} s_{4} \omega /\left[\left(\omega^{2}-{ }^{\mathrm{AZ}} \omega_{4}{ }^{2}\right)^{2}+{ }^{\mathrm{AZ}} \Gamma_{4}{ }^{2} \omega^{2}\right]\right\} \boldsymbol{p}_{k 0}\left(\boldsymbol{x}, \boldsymbol{x}^{\prime}\right)\end{aligned}$ & \begin{tabular}{|l|} 
ternary $\mathrm{ABZ}$ \\
excess in binary $\mathrm{BZ}$ \\
excess in binary $\mathrm{AZ}$ \\
\end{tabular} & $k, 0$ \\
\hline & 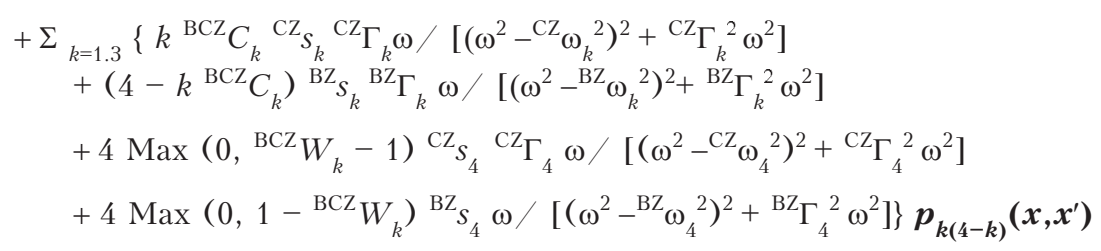 & $\begin{array}{l}\text { ternary } \mathrm{CBZ} \\
\text { excess to binary } \mathrm{CZ} \\
\text { excess to binary } \mathrm{BZ} \\
\end{array}$ & $k,(4-k)$ \\
\hline & 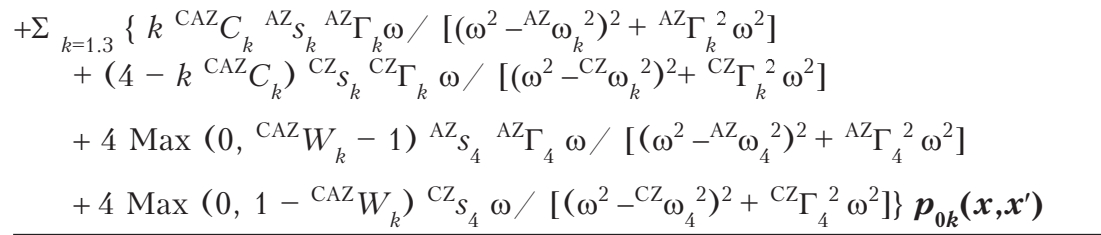 & $\begin{array}{l}\text { ternary } \mathrm{ACZ} \\
\text { excess to binary } \mathrm{AZ} \\
\text { excess to binary } \mathrm{CZ}\end{array}$ & $0, k$ \\
\hline & 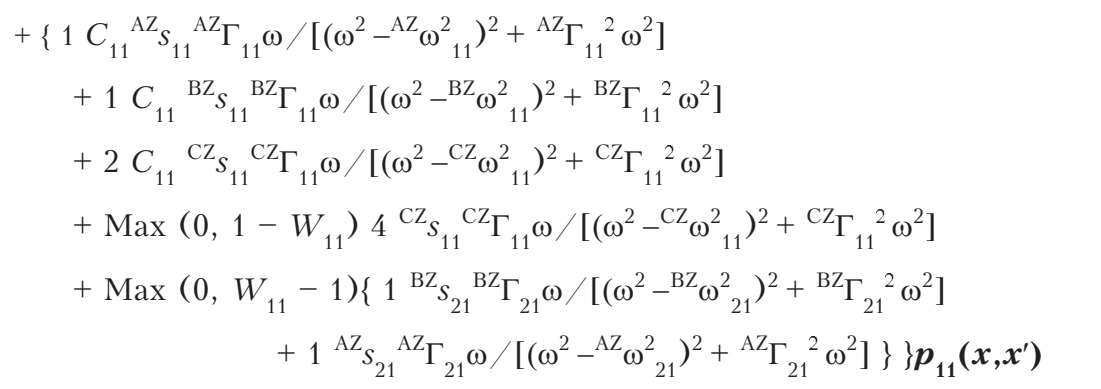 & $\begin{array}{l}\text { excess to binary } \mathrm{CZ} \\
\text { excess to binary } \mathrm{BZ} \\
\text { excess to binary } \mathrm{AZ} \\
\end{array}$ & 1,1 \\
\hline & 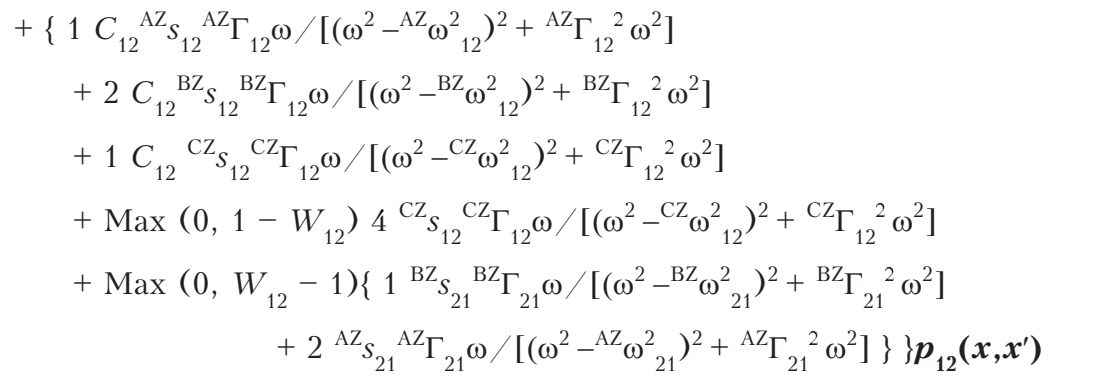 & $\begin{array}{l}\text { excess to binary } \mathrm{CZ} \\
\text { excess to binary } \mathrm{BZ} \\
\text { excess to binary } \mathrm{AZ} \\
\end{array}$ & 1,2 \\
\hline & 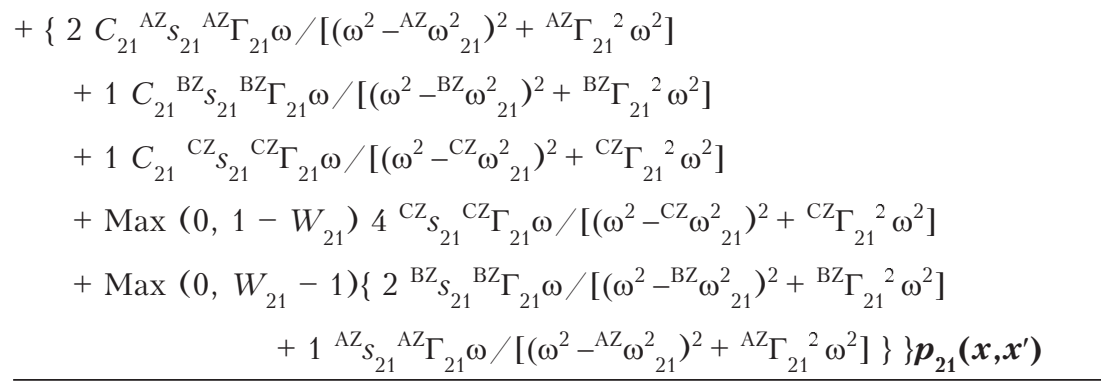 & $\begin{array}{l}\text { excess to binary } \mathrm{CZ} \\
\text { excess to binary } \mathrm{BZ} \\
\text { excess to binary } \mathrm{AZ}\end{array}$ & 2,1 \\
\hline
\end{tabular}


1. B.V. Robouch, A. Kisiel, and J. Konior, J. Alloys Compounds 339, 1 (2002).

2. B.V. Robouch, A. Kisiel, and J. Konior, J. Alloys Compounds 340,13 (2002).

3. B.V. Robouch, E. Burattini, A. Kisiel, A.L. Suvorov, and A.G. Zaluzhnyi, J. Alloys Compounds 359, 73 (2003).

4. B.V. Robouch, E.M. Sheregii, and A. Kisiel, Fiz. Nizk. Temp: 30, 1225 (2004) [Low Temp. Phys. 30, 921 (2004)]

5. B.V. Robouch, E.M. Sheregii, and A. Kisiel, Phys. Status Solidi C1, 3015 (2004).

6. B.V. Robouch, A. Kisiel, A. Marcelli, M. Cestelli Guidi, M. Piccinini, E. Burattini, and A. Mycielski, J. Alloys Compounds 426, 31 (2006).

7. B.V. Robouch, A. Kisiel, A. Marcelli, E.M. Sheregii, M. Cestelli Guidi, M. Piccinini, J. Polit, J. Cebulski, V.I. Ivanov-Omskii, and E. Burattini, J. Alloys Compounds (in submission) (2006).

8. P.A. Lee, P.H. Citrin, P. Eisenberger, and B.M. Kincaid, Rev. Mod. Phys. 53, 769 (1981).

9. B.K. Teo, EXAFS: Basic Principles and Data Analysis, Springer Verlag (1986).

10. F. Stern, Solid State Phys. 15, 299 (1968); Encyclopedia of Physics, S. Flugge (ed.), Springer-Verlag, Berlin (1970), XXV/2c Light and Matter 1c, p.190, Eq.VII.4.19.

11. D.W. Taylor, in book: Optical Properties of Mixed Crystals, R.J. Elliot and I.P. Ipatova (eds.), Elsevier Science Publishers B.V. (1988), p. 35.

12. H.W. Verleur and A.S. Barker, Phys. Rev. 149, 715 (1966); H.W. Verleur and A.S. Barker, Phys. Rev. 155, 750 (1967).

13. S.P. Kozyrev, L.K. Vodopyanov, and R. Tribulet, Solid State Commun. 45, 383 (1983).

14. S. Perkowitz, L.S. Kim, and P. Becla, Phys. Rev. 43, 6598 (1991).

15. S. Perkowitz, L.S. Kim, Z.C. Feng, and P. Becla, Phys. Rev. 42, 1455 (1990).

16. J.C. Mikkelsen and J.B. Boyce, Phys. Rev. Lett. 49, 1412 (1982); J.C. Mikkelsen and J.B. Boyce, J. Phys. Rev. B28, 7130 (1983).

17. A. Balzarotti, N. Motta, A. Kisiel, M. Zimnal-Starnawska, M.T. Czyzyk, and M. Podgorny, Phys. Rev. B31, 7526 (1985); A. Balzarotti, M.T. Czyzyk, A. Kisiel, N. Motta, M. Podgorny, and M. Zimnal-Starnawska, Phys. Rev. B30, 2295 (1984)

18. A. Balzarotti, M.T. Czyzyk, A. Kisiel, P. Letardi, N. Motta, M. Podgorny, and M. Zimnal-Starnawska, Festkörperprobleme 25, 689 (1985).

19. A. Bunker, J. Vac. Sci. Technol. A5, 3003 (1987).

20. A. Marbeuf, D. Ballutaud, R. Triboulet, H. Dexpert, P. Lagarde, and Y. Marfaine, J. Phys. Chem. Solids 50, 975 (1989).

21. R.A. Mayanovic, W.-F. Pong, and B.A. Bunker, Phys. Rev. B42, 11174 (1990).

22. W.-F. Pong, R.A. Mayanovic, B.A. Bunker, J.K. Furdyna, and U. Debska, Phys. Rev. B41, 8440 (1990).

23. Z. Wu, K. Lu, Y. Wang, J. Dong, H. Li, Ch. Li, and Zh. Fang, Phys. Rev. B48, 8694 (1993).

24. M. Zimnal-Starnawska, J. Lazewski, and A. Kisiel, Acta Phys. Pol. 86, 763 (1994).
25. R. Iwanowski, K. Lawniczak-Jablonska, I. Winter, and J. Hormes, Solid State Commun. 97, 879 (1996).

26. J. Lazewski, M. Zimnal-Starnawska, A. Kisiel, F. Boscherini, S. Pascarelli, and W. Giriat, Phys. Status Solidi B197, 7 (1996).

27. N. Happo, H. Sato, T. Mihara, S. Hosokawa, Y. Ueda, and M. Taniguchi, J. Phys. Condens. Matter 8, 4315 (1996).

28. K.E. Miyano, J.C. Woicik, L.H. Robins, C.E. Bouldin, and D.K. Wickenden, Appl. Phys. Lett. 70, 2108 (1997).

29. Sh.M. Islam and B.A. Bunker, Phys. Lett. A156, 247 (1991).

30. A. Kisiel, J. Lazewski, M. Zimnal-Starnawska, E. Burattini, and A. Mycielski, Acta Phys. Pol. A90, 1032 (1996); A. Kisiel, J. Lazewski, M. Zimnal-Starnawska, E. Burattini, and A. Mycielski, J. Phys. (France) C2, 1197 (1997).

31. N. Romcevic, M. Romcevic, A. Golubovic, Le Van Khoi, A. Mcielski, D. Jovanovic, D. Stojanovic, S. Nikolic, and S. Duric, J. Alloys Compounds 397, 52 (2005).

32. B.V. Robouch and A. Kisiel, Acta Phys. Pol. A94, 497 (1998); B.V. Robouch and A. Kisiel, J. Alloys Compounds 286, 80 (1999); B.V. Robouch and A. Kisiel, Synchrotron Radiation Studies of Materials, Proc. 5th Polish National Symp. Synchrotron Radiation Users, Warsaw (1999), J. Gronkowski, M. Lefeld-Sosnowska (eds.), Institute of Experimental Physics, Warsaw Univ., Warsaw (1999), p. 207.

33. Q. Lu, B.A. Bunker, H. Luo, A.J. Kropf, K.M. Kemner, and J.K. Furdyna, Phys. Rev. B55, 9910 (1997).

34. E. Oh, R.G. Alonso, I. Miotkowski, and A.K. Ramdas, Phys. Rev. B45, 10934 (1992).

35. J. Polit, R. Hus, E.M. Sheregii, E. Sciesinska, J. Sciesinski, B.V. Robouch, and A. Kisiel, Far Infrared Spectra in the Tetrahedral Quaternary Alloys (Proc. NGS 10) Proc. 10th Intern. Conf. Narrow Gap Semiconductors and Related Small Energy Phenomena, Physics and Applications, Jpn. Adv. Institute of Science and Technology and Kanazawa Kokusai May 27-31 (2001), Ishikawa, Japan (IPAP) The Institute of Pure and Applied Physics Conf. Series2 (2001), p. 155.

36. E.M. Sheregii, J. Polit, J. Cebulski, P. Sliz, A. Kisiel, M. Piccinini, A. Marcelli, B.V. Robouch, M. Cestelli Guidi, P. Calvani, and V.I. Ivanov-Omskii, Infrared Phys.\&Tech. 49, 13 (2006).

37. B.V. Robouch and A. Kisiel, J. Alloys Compounds 286, 80 (1999).

38. B.V. Robouch, P. Zajdel, A. Kisiel, E.M. Sheregii, A. Marcelli, J. Cebulski M. Cestelli Guidi, M. Piccinini, J. Polit, E. Burattini, and A. Mycielski, Solid State. Commun. (in submission (2006).

39. P. Zajdel, A. Kisiel, J. Polit, B.V. Robouch, E.M. Sheregii, J. Warczewski, J. Cebulski, E. Burattini, A. Marcelli, M. Cestelli Guidi, M. Piccinini, and A. Mycielski, J. Alloys Compounds 426, 12 (2006).

40. J. Polit, E.M. Sheregii, B.V. Robouch, A. Marcelli, J. Cebulski, M. Cestelli Guidi, M. Piccinini, A. Kisiel, P. Zajdel, E. Burattini, and A. Mycielski, J. Appl. Phys. 100, 13521 (2006). 